\title{
BDNF-Dependent Recycling Facilitates TrkB Translocation to Postsynaptic Density during LTP via a Rab11-Dependent Pathway
}

\author{
Shu-Hong Huang, ${ }^{1 *}$ Jue Wang, ${ }^{1 *}$ Wen-Hai Sui, ${ }^{1}$ Bing Chen, ${ }^{1}$ Xiao-Yan Zhang, ${ }^{2}$ Jing Yan, ${ }^{1}$ Zhao Geng, ${ }^{1}$ and Zhe-Yu Chen ${ }^{1}$ \\ ${ }^{1}$ Department of Neurobiology, Shandong Provincial Key Laboratory of Mental Disorders, School of Medicine, Shandong University, Jinan, Shandong \\ 250012, P.R. China, and ${ }^{2}$ Department of Neurobiology, Nanjing Medical University, Nanjing, Jiangsu 210029, P.R. China
}

Brain-derived neurotrophic factor (BDNF) plays an important role in the activity-dependent regulation of synaptic structure and function via tropomyosin related kinase B (TrkB) receptor activation. However, whether BDNF could regulate TrkB levels at synapse during long-term potentiation (LTP) is still unknown. We show in cultured rat hippocampal neurons that chemical LTP (cLTP) stimuli selectively promote endocytic recycling of BDNF-dependent full-length TrkB (TrkB-FL) receptors, but not isoform T1 (TrkB.T1) receptors, via a Rab11-dependent pathway. Moreover, neuronal-activity-enhanced TrkB-FL recycling could facilitate receptor translocation to postsynaptic density and enhance BDNF-induced extracellular signal-regulated kinase and phosphatidylinositol 3-kinase activation and rat hippocampal neuron survival. Finally, we found that cLTP could stimulate the switch of Rab11 from an inactive to an active form and that GTP-bound Rab11 could enhance the interaction between TrkB-FL and PSD-95. Therefore, the recycling endosome could serve as a reserve pool to supply TrkB-FL receptors for LTP maintenance. These findings provide a mechanistic link between Rab11-dependent endocytic recycling and TrkB modulation of synaptic plasticity.

\section{Introduction}

Brain-derived neurotrophic factor (BDNF) plays an important role in the activity-dependent regulation of synaptic structure and function (Arancio and Chao, 2007). BDNF, released in an activity-dependent manner, binds and activates tropomyosin related kinase B (TrkB) receptors (Greenberg et al., 2009). TrkB activation by BDNF initiates three major cascades of signaling pathways: phospholipase $\mathrm{C} \gamma$, phosphatidylinositol 3-kinase (PI3K), and extracellular signal-regulated kinase (ERK) (Huang and Reichardt, 2003; Segal, 2003). BDNF elicits rapid effects on synaptic transmission and membrane excitability primarily via activation of these signaling pathways downstream of its TrkB receptor (Poo, 2001; Rose et al., 2004). Exogenous BDNF promotes the induction of long-term potentiation (LTP) in young hippocampal slices (Figurov et al., 1996). Conversely, LTP was attenuated in slices pretreated with the fusion protein TrkB-IgG

Received July 9, 2012; revised March 28, 2013; accepted April 5, 2013.

Author contributions: S.-H.H. and Z.-Y.C. designed research; S.-H.H., J.W., W.-H.S., B.C., X.-Y.Z., J.Y., and Z.G. performed research; Z.G. contributed unpublished reagents/analytic tools; S.-H.H., J.W., W.-H.S., and B.C. analyzed data; S.-H.H. and Z.-Y.C. wrote the paper.

This work was supported by the National 973 Basic Research Program of China (Grant 2012CB911000 and Grant 2010CB912004), the National Natural Science Foundation of China (Grant 31071254, Grant 31130026, and Grant 31271519), the State Program of National Natural Science Foundation of China for Innovative Research Group (Grant 81021001), the Foundation for Excellent Young Scientist of Shandong Province (Grant BS2010SW022 and Grant BS2010SW023), and the Independent Innovation Foundation of Shandong University. We thank Dr. Wei Lu (Nanjing Medical University, Nanjing, P.R. China) for constructive comments and suggestions.

*S.-H.H. and J.W. contributed equally to this work.

Correspondence should be addressed to Zhe-Yu Chen, Department of Neurobiology, School of Medicine, Shandong University, No. 44 Wenhua Xi Road, Jinan, Shandong 250012, P.R. China. E-mail: zheyuchen@sdu.edu.cn.

DOI:10.1523/JNEUROSCI.3256-12.2013

Copyright $\odot 2013$ the authors $\quad 0270-6474 / 13 / 339214-17 \$ 15.00 / 0$ or in slices obtained from BDNF knock-out mice (Korte et al., 1995; Patterson et al., 1996). Due to its essential role in synaptic plasticity modulation, BDNF is also involved in mediating higher-order activities such as learning, memory, and behavior (Yu et al., 2009; Cunha et al., 2010).

Interestingly, neuronal activity has been shown to increase cell surface TrkB receptors levels, thus facilitating the enhanced responsiveness of active neurons to BDNF (Meyer-Franke et al., 1998; Du et al., 2000). Our recent work also has demonstrated that chemical LTP (cLTP) could induce rapid TrkB insertion into the postsynaptic membrane, which requires the activity of cyclindependent kinase 5 (Zhao et al., 2009). However, in these studies, the TrkB receptor cell surface levels were measured in the absence of BDNF treatment, which reflected TrkB exocytosis from the biosynthetic pathway. BDNF can efficiently drive TrkB receptor internalization and endocytosed TrkB receptors could either traffic to lysosomes for degradation or recycle back to the plasma membrane (Chen et al., 2005; Huang et al., 2009). Multiple lines of evidence have suggested that the endosomal pathway plays a crucial role in synaptic function and plasticity. However, whether BDNF could regulate TrkB levels at the synapse via endosomal pathway during LTP is still unknown.

Recent studies have demonstrated that stimuli that triggered LTP promote recycling of the AMPA receptors containing endosomes for modifying synaptic strength, a process that was regulated by Rab GTPases, molecular motor Myosin V, and adaptor protein GRIP-associated protein-1 (Park et al., 2004; Correia et al., 2008; Wang et al., 2008; Hoogenraad et al., 2010). TrkB plays an important role in modulating synaptic plasticity; however, whether recycling endosomes could provide more TrkB recep- 
tors to synapses during LTP is still unclear. Both full-length TrkB (TrkB-FL) and its isoform T1 (TrkB.T1) receptors, which lack the kinase domain but contain short isoform-specific cytoplasmic domain in its place, are expressed in neurons because of alternative splicing (Klein et al., 1990). We previously found that TrkB-FL and TrkB.T1 receptors traverse divergent recycling pathways after endocytosis (Huang et al., 2009). In this study, we found that cLTP stimuli could selectively promote endocytic recycling of BDNF-dependent TrkB-FL receptors, but not that of the isoform TrkB.T1 receptors, via a Rab11-dependent pathway and also enhanced BDNF-induced downstream signaling.

\section{Materials and Methods}

Reagents and antibodies. Glycine was obtained from Amresco. Human recombinant BDNF was obtained from PeproTech. Rabbit anti-TrkB antibody was purchased from Millipore. Mouse anti-Rab11 antibody was purchased from BD Biosciences. Mouse anti-FLAG (M1, M2), mouse anti-Rab4, and mouse anti-Akt antibodies were purchased from SigmaAldrich. Mouse anti c-Myc and rabbit anti-Trk (C-14) antibodies were purchased from Santa Cruz Biotechnology. Rabbit anti-phospho$\mathrm{Akt}^{\mathrm{S} 473}$, rabbit anti-phospho-CREB1 ${ }^{\mathrm{Ser} 133}$, and rabbit anti-PSD95 antibodies were obtained from Cell Signaling Technology. Rabbit anti-active caspase- 3 antibody was purchased from Abcam. Rabbit anti-CREB1 antibody was obtained from Proteintech Group.

Plasmid constructs and siRNA. Rat TrkB-FL, TrkB.T1, and TrkB mutant constructs were prepared as described previously. The MycRab11WT, Myc-Rab11S25N, and Myc-Rab11Q70L in pCMV were kept in our laboratory. Rat Rab4 cDNA was subcloned into pCDNA3.1Neo expression vector (Invitrogen) using the EcoRI and HindIII sites. The $\mathrm{N}$-terminal Myc tag was added to the $5^{\prime}$ end of Rab4 cDNA by PCR. Myc-Rab4S22N and Myc-Rab4Q67L mutants were made by sitedirected mutagenesis. The DNA sequence corresponding to the rat Sec15C-terminal domain was cloned into the pGEX4T-1 expression vector (GE Healthcare/Pharmacia) with a GST tag at the N terminus. All of the constructs were confirmed by DNA sequencing to exclude potential PCR-introduced mutations. Knock-down of Rab11 and Rab4 expression was performed by RNA interference using specific siRNA oligonucleotides. The target sequences for each of the genes were as follows: rat Rab11a, 5'-GGG CAG UUC CUA CAG AUG A-3'; rat Rab11b, 5' -GAA ACG AGU UCA ACC UAG A-3; rat Rab4a, 5' -CAC CTA CAA TGC GCT TAC TAA T-3'; rat Rab4b, 5' -CGA CCT ACG ACT TCC TCT TCA A-3'.

Hippocampal neuron culture and transfection. Cultured hippocampal neurons were prepared from E18 Sprague Dawley rats of either sex as described previously (Zhao et al., 2009). Neurons were maintained in culture with neurobasal medium supplemented with $2 \%$ B27, $0.5 \mathrm{~mm}$ glutamine, and 100 units $/ \mathrm{ml}$ penicillin/streptomycin. Neurons were plated on poly-D-lysine $(0.1 \mathrm{mg} / \mathrm{ml}$; Sigma-Aldrich)-coated $6 \mathrm{~cm}$ dishes at $3 \times 10^{6}$ cells/dish for biochemical experiments or on poly-D-lysinecoated coverslips at $0.5 \times 10^{6}$ cells/coverslip for immunocytochemistry. Neurons were transfected using Lipofectamine 2000 transfection reagent or Lipofectamine RNAiMAX reagent following the manufacturer's instructions (Invitrogen). All experiments were performed 48 or $72 \mathrm{~h}$ after transfection.

$m E P S C$ in neuronal cultures. Cultured rat hippocampal neurons were grown as described above. Whole-cell recordings were made from these cultures 14-18 d after plating. Recordings from each neurons lasted for at least $70 \mathrm{~min}$ (Man et al., 2003). Recordings in which the series resistance varied by $>10 \%$ were rejected. No electronic compensation for series resistance was used. The intracellular recording (patch electrode) solution contained the following (in mM): $140 \mathrm{CsCl}_{2}, 2.5 \mathrm{EGTA}, 2 \mathrm{MgCl}_{2}$, 10 HEPES, 2 TEA, and $4 \mathrm{~K}_{2} \mathrm{ATP}$, pH 7.3, osmolarity 300-310 mosmol $^{-1}$. Each cell was continuously superfused $(1.0 \mathrm{ml} / \mathrm{min})$ with the $\mathrm{Mg}^{2+}$-free bathing solution containing the following (in $\mathrm{mm}$ ): $140 \mathrm{NaCl}, 1.3 \mathrm{CaCl}_{2}$, $5.0 \mathrm{KCl}, 25 \mathrm{HEPES}, 33$ glucose, $0.0005 \mathrm{TTX}, 0.001$ strychine, and 0.02 bicuculline methiodide, $\mathrm{pH} 7.4$, from a single barrel of a computercontrolled multibarreled perfusion system. Solutions supplemented with glycine were applied from an alternate barrel. mEPSCs were recorded using an Axopatch 700-B amplifier (Molecular Devices), and records were filtered at $2 \mathrm{kHz}$, digitized at $5-10 \mathrm{kHz}$., stored on tape, and subsequently acquired offline with the Mini Analysis Program (Synaptosoft).

Quantitative RT-PCR. Synthesis of TrkB induced by cLTP was measured by quantitative RT-PCR. Serum-starved cultured hippocampal neurons (9 DIV) were pretreated with glycine $(200 \mu \mathrm{M})$ in the bathing solution described above for $3 \mathrm{~min}$ and then transferred to the solution without any added glycine. After that, neurons were stimulated with 50 $\mathrm{ng} / \mathrm{ml} \mathrm{BDNF}$ at $37^{\circ} \mathrm{C}$ for the indicated times. Afterward, neurons were washed with PBS followed by RNA extraction. Total RNA was extracted with TRNzol-A + RNA isolation reagent (TIANGEN) according to the manufacturer's instructions. RT-PCR of TrkB-FL and TrkB.T1 was performed with $1 \mu \mathrm{g}$ of total RNA and RevertAid First Strand cDNA Synthesis Kit (Fermentas). Primer sequences used were as follows: TrkB-FL forward primer: 5'-AAC CAC ACA CAA GGA AGA ACA TCA A-3' and reverse primer: 5'-TGA CAT CAG CGG CAG TTA AGA GGT-3'; TrkB.T1 forward primer: $5^{\prime}$-AAC TCC TGG GAC TAC TGT TGC CTA- $3^{\prime}$ and reverse primer: $5^{\prime}$-AAC AAG CAG GCT GCG GAC ATC TTT- $3^{\prime}$. Primers specific for $\beta$-actin were used as a control (forward: 5'-TCC ATC ATG AAG TGT GAC GT-3' and reverse: $5^{\prime}$-GAG CAA TGA TCT TGA TCT TCA T-3'). Quantitative RT-PCR was performed in a cycler (Light Cycler 2.0; Roche) using SYBR green (Takara). The threshold cycle for each sample was chosen from the linear range and converted to a starting quantity by interpolation from a standard curve run on the same plate for each set of primers. The TrkB-FL and TrkB.T1 mRNA levels were normalized for each well to the $\beta$-actin mRNA levels using the $2^{-\Delta \Delta C T}$ method. Each experiment was repeated five times.

Surface biotinylation assay. Receptors degradation experiments were performed as described previously (Saxena et al., 2005). Briefly, neurons (7 DIV) were transfected with indicated siRNA by Lipofectamine RNAiMAX reagent and experiments were conducted $2 \mathrm{~d}$ after transfection. Serum-starved hippocampal neurons were washed with cold PBS containing $0.1 \mathrm{mM} \mathrm{CaCl}_{2}$ and incubated for $1 \mathrm{~h}$ at $4^{\circ} \mathrm{C}$ with $300 \mu \mathrm{g} / \mathrm{ml}$ sulfo-NHS-biotin to biotinylate surface proteins. Subsequently, the biotinylation was terminated on ice by quenching with Tris-buffered saline (TBS), neurons were treated with glycine $(200 \mu \mathrm{M})$ in the bathing solution described above for $3 \mathrm{~min}$, and then transferred to the solution (without glycine) containing BDNF $(50 \mathrm{ng} / \mathrm{ml})$ for $1 \mathrm{~h}$ in the presence or absence of D-AP5 $(100 \mu \mathrm{M})$ at $37^{\circ} \mathrm{C}$. The cells were then washed twice with TBS and lysed with $500 \mu \mathrm{l}$ of TNE buffer (10 mM Tris, pH 8.0, 150 mM NaCl, 1 mm EDTA, 1\% NP-40, 10\% glycerol with protease inhibitors) on ice. Then lysates were removed to centrifugation for $15 \mathrm{~min}$ at $12,000 \mathrm{rpm}$, and an aliquot of each sample was used for the isolation of biotinylated proteins with streptavidin-conjugated Sepharose beads by incubating overnight at $4^{\circ} \mathrm{C}$ with gentle shaking. The precipitated proteins were then washed three times with TNE buffer and denatured by heating the beads in sample buffer at $95^{\circ} \mathrm{C}$ for $5 \mathrm{~min}$. Proteins were separated by SDS-PAGE followed by anti-TrkB immunoblotting. For estimation of relative amounts of proteins, the exposed films of the immunoblots were scanned and band intensities were measured with MetaMorph software (Universal Imaging).

For surface TrkB levels detection, serum-starved hippocampal neurons (9 DIV) were treated with glycine $(200 \mu \mathrm{M})$ in the bathing solution for $3 \mathrm{~min}$ and then transferred to the solution (without glycine) with BDNF $(50 \mathrm{ng} / \mathrm{ml})$ for $1 \mathrm{~h}$ at $37^{\circ} \mathrm{C}$. Afterward, neurons were washed and incubated for $1 \mathrm{~h}$ at $4^{\circ} \mathrm{C}$ with $300 \mu \mathrm{g} / \mathrm{ml}$ sulfo-NHS-biotin to biotinylate surface proteins. The cells were then washed twice with TBS and lysed with $500 \mu$ l of TNE buffer on ice. Then biotinylated proteins were pulled down by streptavidin-conjugated Sepharose beads. The precipitated proteins were then assessed by anti-TrkB immunoblotting. Each experiment was repeated five times.

Cleavable surface biotinylation assay. Cell surface receptor cleavable biotinylation based recycling assays were performed as described previously (Huang et al., 2009). Serum-starved neurons (9 DIV) were preincubated with leupeptin/Pepstatin A $(100 \mu \mathrm{g} / \mathrm{ml})$ and MG132 $(10 \mu \mathrm{M})$ for $90 \mathrm{~min}$; the cultures were then surface biotinylated as described above with sulfo-NHS-S-S-biotin. Leupeptin/Pepstatin A and MG132 were included in all subsequent steps to inhibit proteolysis. Neurons were then incubated at $37^{\circ} \mathrm{C}$ for $15 \mathrm{~min}$ in media alone (Fig. $2 \mathrm{~A}$, lanes 1 and 2) or in media containing BDNF (Fig. 2A, lanes 3-5) to induce internalization of 
cell surface TrkB receptors. Subsequently, remained cell surface biotin was cleaved by strip solution ( $50 \mathrm{~mm}$ glutathione, $75 \mathrm{~mm} \mathrm{NaCl}, 75 \mathrm{~mm}$ $\mathrm{NaOH}, 0.01 \mathrm{~g} / \mathrm{ml} \mathrm{BSA}, 10 \mathrm{~mm}$ EDTA for all samples except lane 1, which represents total biotinylated TrkB receptors). Afterward, prewarmed bathing solution was added in the presence or absence of glycine for 3 min (Fig. 2A, lanes 4 and 5) and then transferred to fresh solution without glycine. The cells were then incubated at $37^{\circ} \mathrm{C}$ for $30 \mathrm{~min}$ to allow recycling of internalized receptors. This incubation was followed by strip solution treatment again on ice to remove biotin from the surfaceexposed biotinylated receptors that had recycled back to the cell surface during the previous rewarming period and then cells were lysed and biotinylated proteins were precipitated with streptavidin beads. Unrecycled receptors were detected by streptavidin pull down followed by anti-TrkB immunoblotting. The cleavable surface biotinylation assay shown in Figure 5 shared the same protocol as above except that the "surface" and "strip" lane were not shown for clarity. Each experiment was repeated five times.

Coimmunoprecipitation assay. For coimmunoprecipitation (CO-IP), HEK293 cells were electroporated (Amaxa Biosystems) with the indicated constructs. Forty-eight hours after transfection, cells were harvested with TNE buffer. Whole cell lysate was precleared with protein A or G Sepharose beads (Sigma-Aldrich) at $4^{\circ} \mathrm{C}$ for $60 \mathrm{~min}$. The cleared supernatant was incubated overnight at $4^{\circ} \mathrm{C}$ with the indicated antibodies, followed by $2 \mathrm{~h}$ of incubation at $4^{\circ} \mathrm{C}$ with protein $\mathrm{A}$ or G-Sepharose beads. Finally, the beads were washed five times with TNE buffer, eluted by boiling in sample buffer for SDS-PAGE, and further immunoblot analysis was conducted with the indicated antibodies. Each experiment was repeated at least three times.

Analysis of TrkB receptor recycling using fluorescence ratio microscopy. The TrkB receptor recycling assay was performed as described previously (Huang et al., 2009). Hippocampal neurons (7 DIV) were transfected with the indicated constructs using Lipofectamine 2000 reagent and experiments were conducted $2 \mathrm{~d}$ after transfection. Hippocampal neurons expressing FLAG-tagged TrkB receptors/FLAG-tagged TrkB mutants were serum starved overnight and incubated with Alexa Fluor 488conjugated anti-FLAG antibody (M1) in neurobasal medium for $15 \mathrm{~min}$ at $4^{\circ} \mathrm{C}$. Neurons were then incubated in the presence of BDNF $(50 \mathrm{ng} / \mathrm{ml})$ for $30 \mathrm{~min}$ to drive internalization $\left(37^{\circ} \mathrm{C}\right)$ and then quickly washed 3 times with ice-cold PBS containing $1 \mathrm{~mm}$ EDTA to dissociate the binding of Alexa Fluor 488-conjugated M1 anti-FLAG antibody with uninternalized TrkB. Next, neurons (9 DIV) were treated with glycine (200 $\mu \mathrm{M})$ in the bathing solution for $3 \mathrm{~min}$ and then changed to fresh solution(without glycine) containing Alexa Fluor 594-conjugated antimouse IgG secondary antibody at $37^{\circ} \mathrm{C}$ for $30 \mathrm{~min}$ to label receptors that returned back to the cell surface. The neurons were then immediately fixed by $4 \%$ paraformaldehyde in PBS. For each experiment, two parallel control groups were included, one in which cells were fixed after the 15 min incubation in the absence of BDNF and without the EDTA stripping step (100\% surface control) and one in which cells were fixed immediately after the EDTA-mediated stripping step ( $0 \%$ recycled control). Images were acquired using an epifluorescence microscope (Eclipse TE 2000-U; Nikon), and the amount of recycling was quantitated using MetaMorph software. Recycled receptors were calculated as described previously (Chen et al., 2005; Huang et al., 2009). The percentage of recycled receptors was calculated from the red/green ratios determined in the control condition using the following formula: $(E-Z) /(C-Z) \times$ 100 , where $E$ is the mean ratio for the "recycled" group, $Z$ is mean ratio for the $0 \%$ recycled control group, and $C$ is the mean ratio for the $100 \%$ surface control group. More than 30 cells/construct/condition were analyzed at random in this manner for each experiment. Each experiment was repeated at least three times.

Colocalization studies. Immunofluorescence assays were performed as described previously (Huang et al., 2009). To visualize internalized TrkB, neurons at $18 \mathrm{DIV}$, transfected with the indicated constructs, were fed with Alexa Fluor 488-conjugated anti-FLAG antibody (M1) to label surface TrkB at $4^{\circ} \mathrm{C}$. After $30 \mathrm{~min}$ of BDNF-induced internalization, remaining surface 488 -M1 antibodies were stripped by PBS/EDTA. Subsequently, neurons were fixed with $4 \%$ paraformaldehyde in PBS for 10 min and permeabilized by treatment with $0.4 \%$ Triton X-100 in TBS (20 min), followed by immunostaining with primary and secondary antibodies.

To visualize the colocalization between recycled TrkB-FL with PSD-95 in transfected hippocampal neurons (21 DIV), cells were fed with antiFLAG antibody (M1) to label surface TrkB at $4^{\circ} \mathrm{C}$. After BDNF treatment for $30 \mathrm{~min}$ to induce internalization, remaining surface M1 antibodies were stripped by PBS/EDTA and neurons were then treated with glycine $(200 \mu \mathrm{M})$ in the bathing solution for $3 \mathrm{~min}$. Additional incubation (at $37^{\circ} \mathrm{C}$ for $30 \mathrm{~min}$ ) with Alexa Fluor 488 - or CY5-conjugated goat-antimouse secondary antibodies was performed to specifically label the recycled TrkB receptors. Neurons were then fixed with $4 \%$ paraformaldehyde in PBS for $10 \mathrm{~min}$ and permeabilized by treatment with $0.4 \%$ Triton X-100 in TBS (20 min), followed by immunostaining with PSD-95 antibodies. All immunostained cells were observed with a Zeiss LSM780 microscope (Microstructural Platform of Shandong University), and quantification of pixel-by-pixel fluorescence intensity correlations was performed using MetaMorph software. Each experiment was repeated at least three times.

Preparation of hippocampal slice cultures. Organotypic slice cultures were prepared from postnatal day 6 rat hippocampus as described previously (De Simoni and Yu, 2006). Briefly, after decapitation, the hippocampi were cut into $400-\mu \mathrm{m}$-thick slices with a vibrating microtome (Leica Microsystems) and explanted onto Millicell culture plate inserts (Millipore). The inserts were placed in 6-well plates and incubated in culture medium containing 50\% MEM, 18\% EBSS, 25\% horse serum, 2 $\mathrm{mm}$ glutamine, and $100 \mathrm{units} / \mathrm{ml}$ penicillin/streptomycin. Slices were incubated in $5 \% \mathrm{CO}_{2}$ at $37^{\circ} \mathrm{C}$ for $9 \mathrm{~d}$. The culture medium was completely replaced every 2-3 d. The hippocampal slice cultures (P6 + 9 DIV) were treated with recombinant BDNF $(50 \mathrm{ng} / \mathrm{ml})$ for $1 \mathrm{~h}$ and TrkB/ PSD-95 association was then examined by CO-IP assay. Each experiment was repeated three times.

Subcellular fractionation. Neurons were treated with or without glycine $(200 \mu \mathrm{M})$ in the bathing solution for $3 \mathrm{~min}$ and then transferred to the solution without glycine for $30 \mathrm{~min}$. Fractionation of membrane and cytosol protein was isolated using the ProteoJET Membrane Protein Extraction Kit (Fermentas) according to the manufacturer's instructions. The experiment was repeated three times.

In vitro assay to test the binding of Rab11 to Sec15C. The GST-Sec15C (397-804 aa) fusion proteins were expressed in BL21 Escherichia coli (DE3 strain; Novagen) and immobilized on glutathione-Sepharose 4B beads (GE Healthcare). The purified GST-Sec15C bound beads were incubated with lysates from neurons treated with indicated agents at $4^{\circ} \mathrm{C}$ overnight. After an extensive wash with TNE buffer, the bound proteins were analyzed by SDS-PAGE, followed by staining with Coomassie blue (Sigma-Aldrich) or immunoblotting with anti-Rab11 antibody. The experiment was repeated three times.

TUNEL analysis. For TUNEL/DAPI analysis, hippocampal neurons were plated on poly-D-lysine-coated cover glasses in 6-well plates and maintained in culture with neurobasal medium supplemented with $2 \%$ B27, $0.5 \mathrm{~mm}$ glutamine, and 100 units/ml penicillin/streptomycin. Neurons (7 DIV) were transfected with indicated siRNA by Lipofectamine RNAiMAX reagent and experiments were conducted $2 \mathrm{~d}$ after transfection. B27-starved neurons were treated with different drugs (BDNF 50 $\mathrm{ng} / \mathrm{ml}$ and/or bicuculline $10 \mu \mathrm{M}$ ). After $48 \mathrm{~h}$ in culture, the cell death was assessed using the In Situ Cell Death Detection Kit (Roche) and DAPI staining (Sigma-Aldrich). Neurons were visualized with a fluorescence microscope. For each condition, images of 12 preselected fields (totaling 1500-2000 cells) were captured in a nonbiased manner from each of three separate assays. The fraction of dead cells was determined by dividing the number of nuclei exhibiting TUNEL staining by the number of DAPI-positive nuclei. The experiment was repeated three times.

Statistical analysis. All statistical analysis was performed using SPSS software. Student's $t$ test was used to assess significance for data within two groups. Multiple statistic comparisons were analyzed using one-way ANOVA followed by post hoc tests. TrkB vesicles distribution in spines was evaluated by $\chi^{2}$ analysis. Data are presented as mean \pm SEM and significance was set at $p<0.05$. 


\section{Results}

Neuronal activity blocks BDNF-induced TrkB-FL receptor degradation

It has been established that TrkB receptors are degraded via lysosomes in a BDNF-dependent manner in cell lines such as PC12 cells and in primary neuronal cultures (Chen et al., 2005; Huang et al., 2009). First, we investigated whether neuronal activity could regulate BDNF-induced TrkB degradation using a cell surface biotinylation assay. We used a cell culture model using glycine stimulation to activate NMDA receptors, which is used to induce cLTP in cultured hippocampal neurons (Lu et al., 2001; Fig. 1A). Glycine-induced cLTP could increase the number of functional AMPA-type glutamate receptors at the postsynaptic membrane, leading to an increase in AMPAR-mediated transmission at excitatory synapses, as in other LTP models (Isaac et al., 1995; Liao et al., 1995; Lu et al., 2001; Park et al., 2004). As shown in Fig. 1B, application of the NMDAR co-agonist glycine $\left(200 \mu \mathrm{M} ; 3 \mathrm{~min}\right.$ ) produced LTP of $\mathrm{mEPSC}_{\mathrm{AMPA}}$ by the persistent increase in both amplitude and frequency, as reported previously (Lu et al., 2001). To further confirm the effectiveness of glycine in stimulating neurons, we detected the phosphorylation of CREB1 by immunoblotting upon glycine treatment. As shown in Figure $1 D$, the phosphorylation level of CREB1, which is a well known target for LTP (Ghosh et al., 1994; Moore et al., 1996), was significantly increased 15 min after glycine treatment. For the surface biotinylation assay to detect the degradation of internalized TrkB upon BDNF and glycine application, hippocampal neurons were biotinylated, pretreated with glycine $(200 \mu \mathrm{M})$ for $3 \mathrm{~min}$, followed by BDNF (50 ng/ml) application for $1 \mathrm{~h}$, lysed, pulled down with streptavidin beads, and immunoblotted for TrkB antibodies, which allowed for assessment of proteolysis of the endocytosed TrkB receptors. We found that glycine pretreatment could block the BDNF-induced TrkB-FL receptor degradation, which was abolished by coapplication of the NMDA receptor antagonist D-AP5 (Fig. 1E). In contrast, ligand-induced TrkB.T1 receptor degradation was not significantly changed upon glycine pretreatment (Fig. 1E), suggesting that cLTP stimuli could specifically block BDNF-induced TrkB-FL receptor degradation.

We also investigated whether the blockade of BDNF-induced TrkB-FL receptor degradation by glycine pretreatment could modulate TrkB receptor surface levels. After glycine treatment and $1 \mathrm{~h}$ of BDNF treatment, surface receptor biotinylation was performed and the TrkB receptors remaining on the cell surface could be selectively pulled down by streptavidin beads. Using this approach, we found that under basal conditions, BDNF treatment led to a significant reduction in surface receptor levels of TrkB-FL ( 55\%), but not TrkB.T1, which was blocked by glycine treatment (Fig. $1 F$ ). The blockade of BDNF-induced decrease in TrkB-FL surface levels upon glycine stimuli might be due to the results of either increased TrkB receptor synthesis or enhanced TrkB receptors recycling back to the cell surface. We performed a RT-PCR assay and found that there were no significant changes in the transcriptional levels of TrkB-FL or TrkB.T1 at the $1 \mathrm{~h}$ time point after glycine and BDNF application (Fig. $1 G)$. In addition, cycloheximide $(20 \mu \mathrm{g} / \mathrm{ml})$ or rapamycin $(20$ $\mathrm{nm}$ ) was used to inhibit the global or local protein synthesis, respectively (Cracco et al., 2005). As shown in Figure $1 H$, in the presence of both inhibitors, glycine pretreatment could still block the BDNF-induced decrease in TrkB-FL surface levels, which excluded the possibility that the newly synthesized TrkB receptors were involved in the action of glycine and suggested that glycine stimuli might promote TrkB-FL recycling.

\section{cLTP stimuli enhances the postendocytic recycling of} TrkB-FL receptors, but not TrkB.T1 receptors

We hypothesized that the blockade of BDNF-induced decrease in TrkB-FL surface levels upon cLTP stimuli may be due to altered TrkB-FL postendocytic recycling. First, a cleavable biotinylation assay was used to measure TrkB receptor postendocytic recycling. The lysosomal protease inhibitor leupeptin and the proteasome inhibitor MG132 were included throughout the experiment to block TrkB degradation and glycine was applied after the internalization step (Fig. 2A). We found a significant decrease of the remaining internalized TrkB-FL receptors after the rewarming process upon glycine treatment (Fig. $2 A$ ), which suggested that glycine treatment induced more internalized TrkB-FL receptors to recycle back to the cell surface to be cleaved. However, the remaining TrkB.T1 receptor levels were not changed upon cLTP stimuli. A live cell ratiometric fluorescence-based recycling assay, which has been used in our previous studies (Chen et al., 2005; Huang et al., 2009), was also used to measure the TrkB-FL and TrkB.T1 receptors recycling under various conditions (Fig. 2B). Hippocampal neurons were transfected with FLAG epitopetagged TrkB-FL or TrkB.T1 receptors. A calcium-sensitive fluorescent anti-FLAG antibody (M1) was used to label surface TrkB receptors. The neurons were then incubated in presence of BDNF, followed by a PBS/EDTA wash to remove the surfacebound antibody. Neurons were then incubated in presence of Alexa Fluor 594-coupled anti-mouse IgG for $30 \mathrm{~min}$, which allowed the detection of TrkB that recycled back to the neuronal surface (see Materials and Methods for details). Quantification of these results by ratiometric analyses confirmed that glycine treatment significantly increased the levels of BDNF-dependent TrkB-FL recycling by 2 -fold (from $25 \pm 2 \%$ to $59 \pm 2 \%$ ), whereas TrkB-T1 recycling levels were not affected by glycine stimulation (from $63 \pm 2 \%$ to $64 \pm 2 \%$; Fig. $2 B, C$ ). Moreover, the glycineinduced increase in TrkB-FL recycling was prevented by coapplication of $\mathrm{D}-\mathrm{AP} 5$, indicating a requirement for NMDA receptor activation (Fig. 2B,C). To examine the neuronal-activityenhanced TrkB-FL recycling under more physiological conditions, hippocampal neurons were treated with the depolarizing agent $\mathrm{KCl}(50 \mu \mathrm{M})$ or with bicuculline $(10 \mu \mathrm{M})$, which could enhance neuronal activity by blocking inhibitory $\mathrm{GABA}_{\mathrm{A}}$ receptors (Curtis et al., 1971). Compared with basal status, $\mathrm{KCl}$ or bicuculline treatment could also induce a substantial increase in TrkB-FL recycling (Fig. 2D). These results suggest that neuronal activity could significantly increase the BDNF-dependent postendocytic recycling of TrkB-FL receptors, but not TrkB.T1 receptors, explaining the blockade effect of cLTP stimuli on BDNF-induced TrkB-FL degradation.

To define the potential region in TrkB-FL receptor that is responsible for the differential response of TrkB-FL and TrkB.T1 recycling to CLTP stimuli, various domains ( $\mathrm{C}$ terminus, kinase domain) were deleted from TrkB-FL and BDNF-dependent recycling in hippocampal neurons at basal or cLTP stimulated condition was assessed with the ratiometric recycling assay (Fig. $3 B, C$ ). The TrkB-FL mutant lacking the kinase domain (TrkB $\Delta \mathrm{TK}$ ) had increased recycling levels and lost the ability to increase recycling in response to glycine stimuli (Fig. $3 \mathrm{~B}, \mathrm{C}$ ). This result is consistent with the subsequent finding that the recycling of TrkB-kinase dead (TrkB.KD), which has a point mutation (K571A) in the kinase domain established to abolish kinase activity (Huang et al., 2009), also showed no response to glycine treatment (Fig. $3 B, C$ ). These results indicate that the altered TrkB recycling in response to cLTP stimuli depends on TrkB kinase activity. 
A

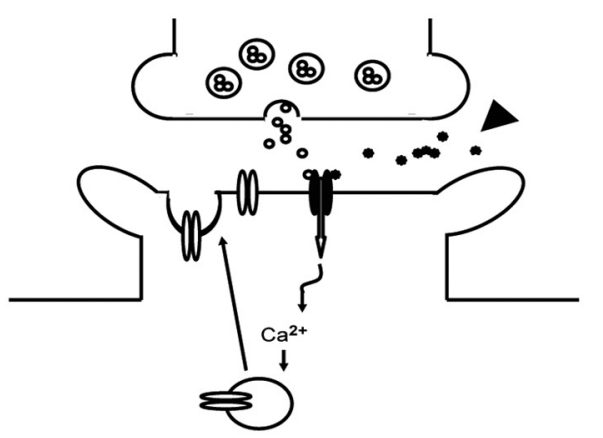

D

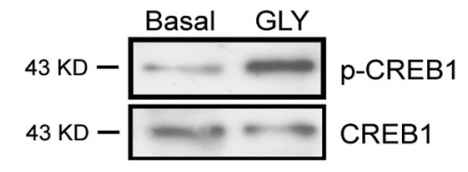

E

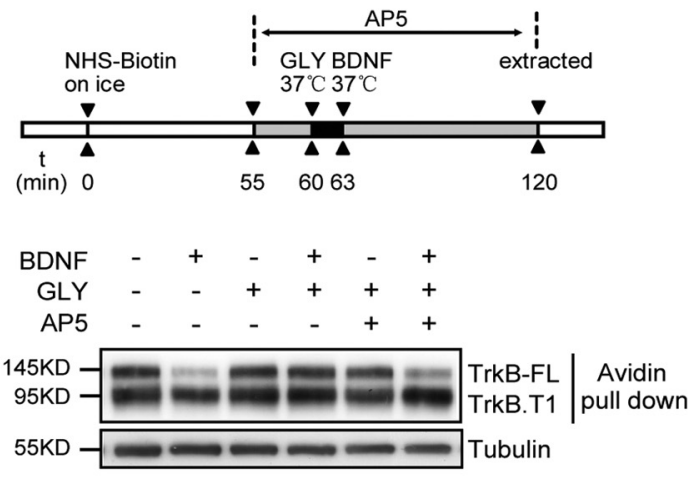

F
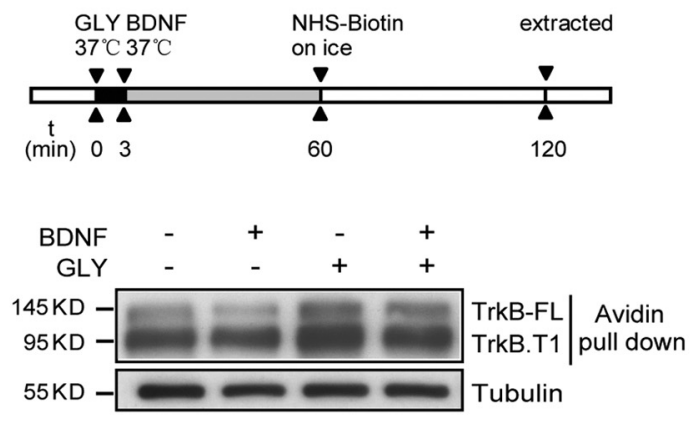

G

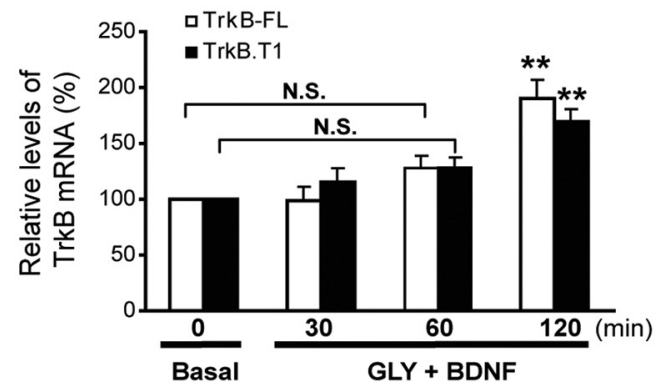

B Basal

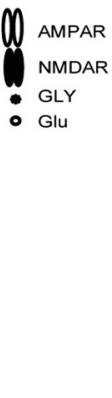

C
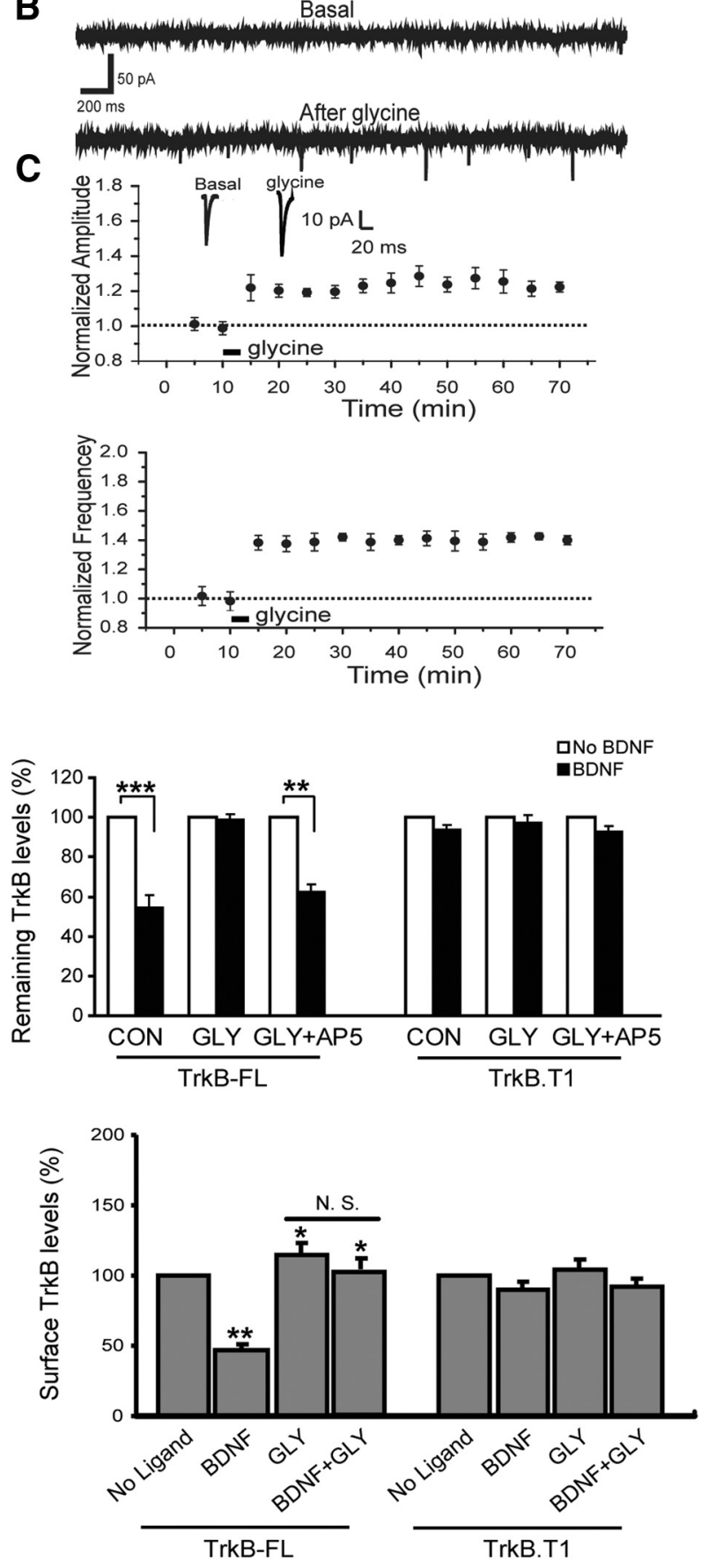

H

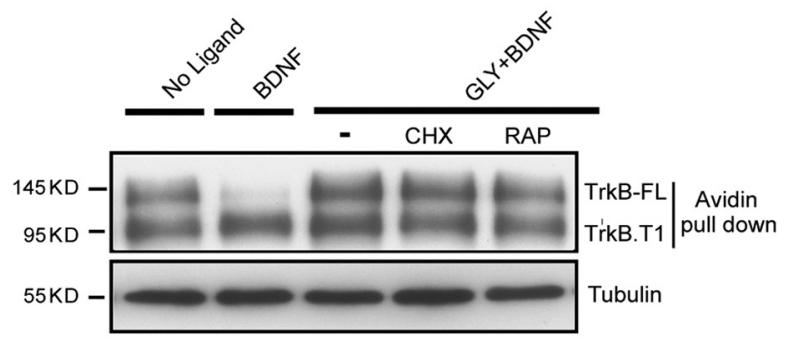

Figure 1. CLTP stimuli block BDNF-induced TrkB-FL receptor degradation. $A$, Schematic diagram of the CLTP induced by glycine. $B$, Example of continuous recordings from individual neurons immediately before (Basal) and 20 min after glycine (Glycine). C, Averaged responses from 6 cells $(n=80-120$ events; 5 min per average; $p<0.01)$ are shown over a 60 min duration of recording. The amplitudes and frequencies of mEPSCs were compared. Inset, example mEPSC traces before and after glycine. D, Immunoblots of phospho-CREB1 and CREB1. (Figure legend continues.) 
TrkB-FL and TrkB.T1 receptors are sorted into distinct recycling pathways via Rab11 and Rab4, respectively

Upon delivery to the early endosomes, internalized receptors then recycle to the plasma membrane via two distinct recycling pathways: Rab4 regulates fast recycling from early endosomes to the cell surface (Sheff et al., 1999), whereas Rabll plays a role in slow recycling from perinuclear recycling vesicles back to the plasma membrane. It has been previously reported that internalized $\beta(2)$-adrenergic receptors efficiently recycled back to the plasma membrane via direct interaction with Rab11 (Parent et al., 2009). We previously found that TrkB.T1 receptors predominantly recycle back to the cell surface by a "default" mechanism, whereas endocytosed TrkB-FL receptors are sorted into a "regulated" recycling pathway that undergoes sequence-directed recycling and depends on its tyrosine kinase activity and the hepatocyte growth factor-regulated tyrosine kinase substrate (Huang et al., 2009). We speculated that the postendocytic recycling of TrkB-FL and TrkB.T1 receptors may be regulated by different Rab proteins. We first sought to determine whether Rab11 or Rab4 could interact with TrkB-FL by CO-IP studies. We cotransfected N-terminal Myc tagged Rab11 or Rab4 with FLAGTrkB-FL into HEK293 cells. Interestingly, after immunoprecipitation of Rab proteins with Myc antibodies, an association of TrkB-FL with Rab11 but not Rab4 was observed, as assessed by immunoblotting analysis using FLAG antibodies (Fig. 4A). In addition, we found that the constitutively inactive GDP-bound form of Rab11 (Rab11S25N) could bind more tightly with TrkB-FL compared with the constitutively active GTP-bound form of Rab11 (Rab11Q70L) (Fig. 4A), which was consistent with the previous finding that $\beta(2)$-adrenergic receptors interact preferentially with the GDP-bound form of Rab11 (Parent et al., 2009). In HEK293 cells with Rab11 and TrkB-FL, TrkB.T1, or TrkB.KD ectopic overexpression, only TrkB-FL can be pulled down by Rab11, whereas no association between TrkB.T1/TrkB.KD and Rab11 was detected (Fig. $4 B$ ), which suggests that the kinase activity is required for the TrkB-FL/Rab11 interaction. To exclude the possibility that the association between Rab11 and TrkB-FL was due to an ectopic overexpression artifact, an endogenous CO-IP assay was performed in cultured hippocampal neuron lysate. As shown in Figure 4C, we found that Rab11 coimmunoprecipitated with TrkB-FL under endogenous conditions. The endogenous Rab11/TrkB-FL interaction was significantly enhanced by BDNF treatment and abolished in the presence of the specific Trk kinase inhibitor K252a (Fig. 4C), which further confirms that their interaction relies on TrkB ki-

\section{$\leftarrow$}

(Figure legend continued.) Neurons were pretreated with glycine $(200 \mu \mathrm{m})$ for $3 \mathrm{~min}$ and lysed 15 min after glycine was washed out. E, Left: Hippocampal neurons ( 9 DIV) were surfaced biotinylated and treated with BDNF $(50 \mathrm{ng} / \mathrm{ml})$ under the indicated conditions for $1 \mathrm{~h}$. Surfacelabeled receptors were detected by streptavidin pull-down followed by anti-TrkB immunoblotting. Right: Densitometric quantification of the results shown on the left. Data are shown as the mean \pm SEM $\left(n=5,{ }^{* *} p<0.01\right.$ and ${ }^{* * *} p<0.001$ relative to the no BDNF control of each group, Student's t test). $\boldsymbol{F}$, Left: Immunoblots of surface TrkB. Neurons ( 9 DIV) were treated with various agents as indicated, followed by biotinylation. Right: Densitometric quantification of the results shown on the left. Data are shown as the mean $\pm \operatorname{SEM}\left(n=3,{ }^{*} p<0.05\right.$ and ${ }^{* *} p<$ 0.01 relative to the no ligand control, Student's $t$ test) N.S. indicates not significant. $G$, Relative mRNA levels of TrkB-FL and TrkB.T1 in cultured hippocampal neurons (9 DIV) analyzed by real-time RT-PCR. Neurons were pretreated with glycine $(200 \mu \mathrm{m})$ for 3 min, followed by BDNF $(50 \mathrm{ng} / \mathrm{ml})$ application for the indicated times. Data are shown as the mean \pm SEM $(n=5$, ${ }^{* *} p<0.01$ compared with baseline; Student's $t$ test). $\boldsymbol{H}$, Surface TrkB levels were detected by surface biotinylation as in $\boldsymbol{F}$. Neurons ( 9 DIV) were pretreated with cycloheximide (CHX; 20 $\mu \mathrm{g} / \mathrm{ml}$ ) or rapamycin (RAP; $20 \mathrm{~nm}$ ) to inhibit the protein translation. nase activity. Furthermore, we compared the subcellular colocalization of endocytosed TrkB receptors with Rab4 or Rab11 in cultured hippocampal neurons. We found that most of the internalized TrkB-FL receptors were colocalized with Rab11 but not Rab4 containing vesicles, whereas internalized TrkB.T1 receptors were mainly colocalized with Rab4 (Fig. 4D,E). These results suggest that the internalized TrkB-FL and TrkB.T1 receptors may traverse the Rab11- or Rab4-dependent recycling pathway, respectively.

Next we investigated whether Rab11 or Rab4 are functionally required for the postendocytic recycling of TrkB receptors using the ratiometric fluorescence-based recycling assay. Overexpression of Rab11S25N, which is deficient in GTP binding and functions as a dominant-negative mutant of Rab11 (Ascaño et al., 2009), significantly decreased, whereas the constitutively active form of Rab11 (Rab11Q70L) increased the recycling of TrkB-FL receptor (Fig. 5A,B). However, both Rab11 S25N and Q70L mutants failed to alter TrkB.T1 recycling (Fig. 5C,D). Conversely, the GDP-locked form of Rab4 (Rab4S22N) could significantly inhibit the recycling of TrkB.T1, whereas the GTP-locked form of Rab4 (Rab4Q67L) enhanced TrkB.T1 recycling (Fig. 5C,D). Neither Rab4S22N nor Rab4Q67L had a detectable effect on the recycling of TrkB-FL (Fig. 5A,B). These results demonstrate that Rab11 and Rab4 are required for the postendocytic recycling of TrkB-FL and TrkB.T1 receptors, respectively. To further confirm the role of Rab11 and Rab4 in mediating recycling of the two TrkB receptors, we demonstrated that siRNA knocking down Rab11 or Rab4 expression could, respectively, block the recycling of TrkB-FL or TrkB.T1 (Fig. 5A-D). Interestingly, Rab11, but not Rab4, mutants abolished the glycine-induced increase in TrkB-FL recycling (Fig. 5A,B), which suggested that the Rab11dependent, but not the Rab4-dependent, pathway mediated cLTP-enhanced TrkB-FL recycling. Furthermore, another set of experiments was performed to investigate the recycling of TrkB at the endogenous levels upon Rab11 or Rab4 knock-down by cleavable surface biotinylation assay. We found that knocking down Rab11 by siRNA decreased the endogenous recycling of TrkB-FL, but not TrkB.T1, whereas Rab4 knock-down abolished TrkB.T1 recycling at the endogenous levels. Moreover, cLTPenhanced TrkB-FL recycling was also blocked at the endogenous levels by Rab11, but not Rab4, knock-down (Fig. $5 E, F$ ). We subsequently examined whether Rab11- or Rab4-dependent recycling could affect the endogenous surface levels of TrkB receptors. The cultured neurons were transfected with Rab11 or Rab4 siRNA and, $48 \mathrm{~h}$ later, treated with $50 \mathrm{ng} / \mathrm{ml} \mathrm{BDNF}$ for $1 \mathrm{~h}$ and surface biotinylation was performed to label surface proteins. We found that blockade of Rab11-dependent recycling by Rab11 siRNA markedly accelerated BDNF-induced reduction in endogenous surface receptor levels of TrkB-FL, but not TrkB.T1. Whereas Rab4 knock-down decreased surface TrkB.T1, it had minimal effects on TrkB-FL receptor surface levels after BDNF treatment (Fig. 5G-I). These results suggest that Rab11 and Rab4, respectively, mediate TrkB-FL and TrkB.T1 receptor postendocytic recycling and thus modulate their surface levels after BDNF treatment.

\section{Increased recycling upon cLTP stimuli enhances BDNF triggered TrkB downstream signaling}

To assess the functional consequences of the increased TrkB-FL recycling upon cLTP stimuli, we investigated the BDNF-induced signaling in cultured hippocampal neurons transfected with scrambled or Rab11 siRNA because the altered TrkB-FL recycling may affect downstream signaling. We chose two time points (5 

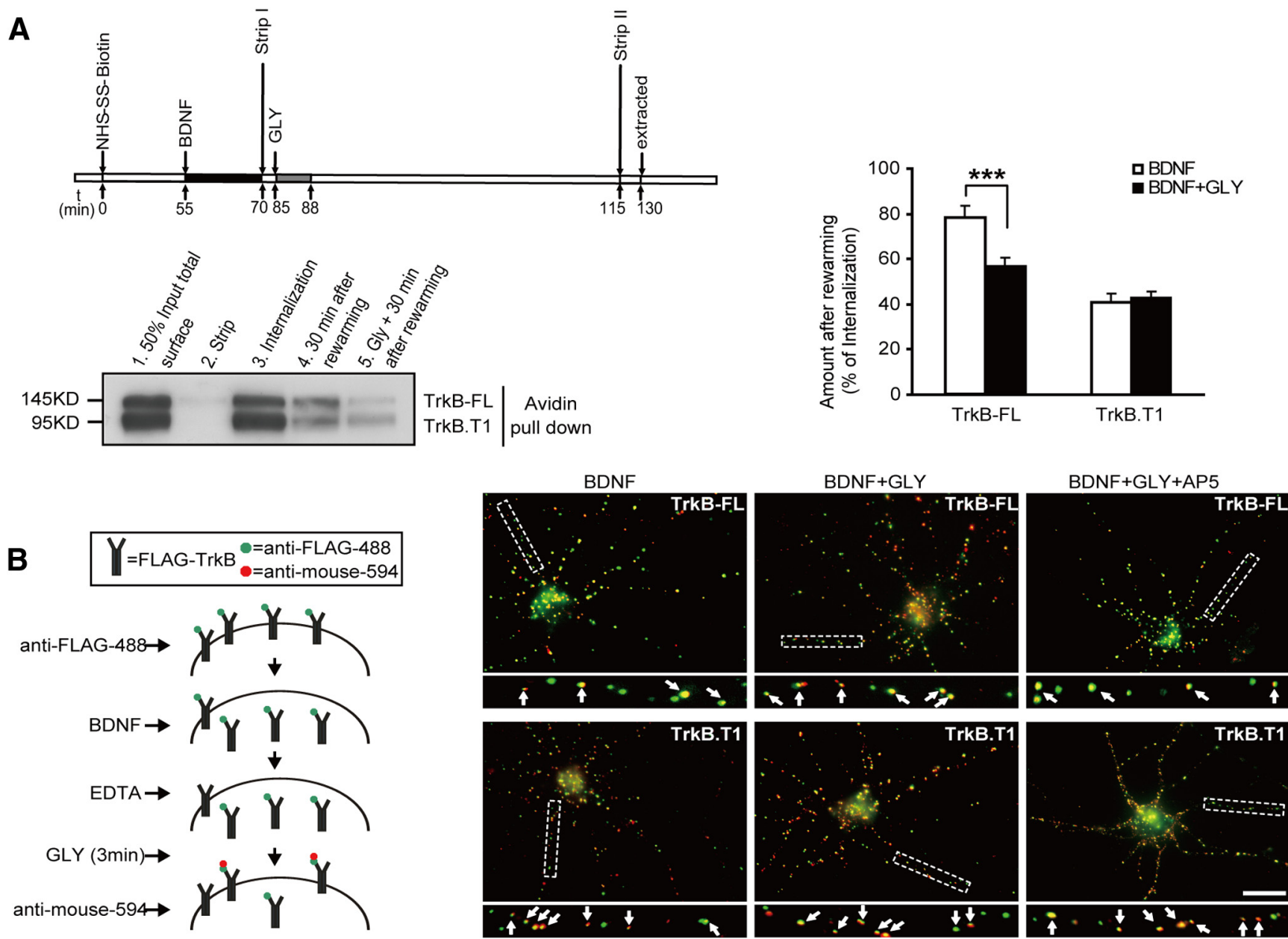

C
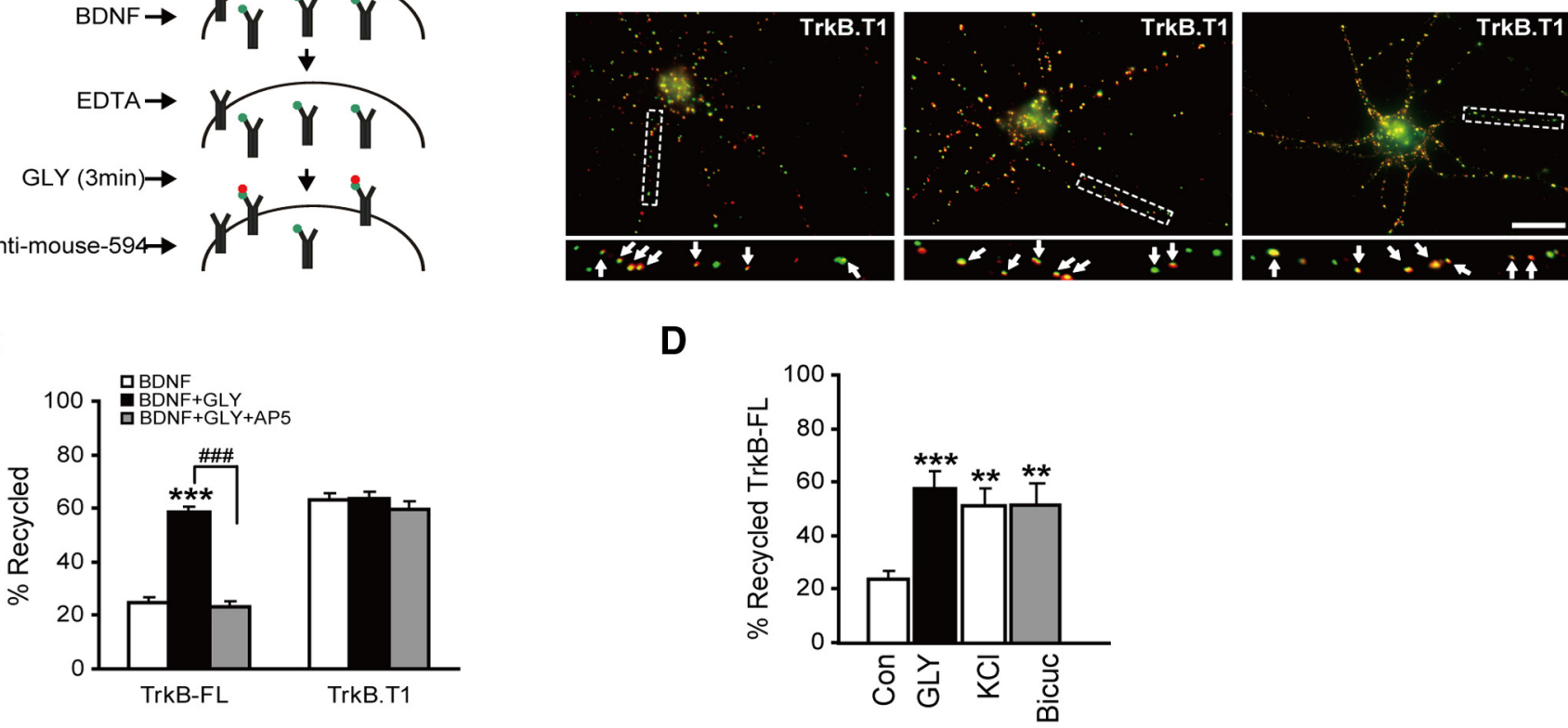

Figure 2. CLTP stimuli enhance the postendocytic recycling of TrkB-FL receptors, but not TrkB.T1 receptors. $A$, Left: TrkB recycling levels were measured by cleavable surface biotinylation (see Materials and Methods for details). Lane 1 refers to the total biotinylated TrkB receptors on neuronal surface; lane 2 shows a control for the efficiency of the stripping procedure; lane 3 shows the internalized biotinylated TrkB receptors before rewarming; lane 4 shows un-recycled (remaining) TrkB receptors after 30 min rewarming under basal condition; lane 5 shows un-recycled (remaining) TrkB receptors after 30 min rewarming upon CLTP stimuli. Right: Bar graphs representing means \pm SEM $\left(n=5,{ }^{* * *} p<0.001\right.$, Student's $t$ test). $B$, Left: Schematic of live cell ratiometric fluorescence-based recycling assay. Right: Live-cell ratiometric assay labeling of recycled TrkB under the indicated conditions (see Materials and Methods for details). The internalized TrkB is shown in green and the recycled TrkB is shown in red. Bottom: Enlarged images of framed regions, with the white arrows indicating the recycled TrkB. Scale bars, $20 \mu \mathrm{m}$. C, Quantitation of recycled TrkB levels in $\boldsymbol{B}$ as described in Materials and Methods. Graphs represent means \pm SEM of five independent experiments ( $n \geq 30$ cells for each condition per experiment, ${ }^{* * *} p<0.001,{ }^{\# \# \#} p<0.001$, one-way ANOVA). $\boldsymbol{D}$, Quantitation of recycled TrkB-FL levels treated with indicated drugs. Graphs represent means \pm SEM of five independent experiments ( $n \geq 30$ cells for each condition per experiment, ${ }^{* *} p<0.01,{ }^{* * *} p<0.001$, one-way ANOVA).

min and $1 \mathrm{~h}$ ) to distinguish the transient and sustained signaling. Activation of ERK1/2 and PI3K-AKT, both of which are well established downstream targets of TrkB activation, was monitored by immunoblotting. At the $5 \mathrm{~min}$ time point, BDNFtriggered TrkB phosphorylation and its downstream signaling were not altered upon Rab11 knock-down (Fig. 6A-D), which suggested that the transient activation of TrkB and its down- stream signaling were independent of recycling and degradation. In contrast, glycine pretreatment significantly enhanced the BDNF-induced TrkB-FL, ERK1/2, and AKT activation at the $1 \mathrm{~h}$ time point in the control group (transfected with scrambled siRNA; Fig. $6 E-H)$. Neurons transfected with Rab11 siRNA had phosphorylation levels of ERK1/2 and AKT that were attenuated by $\sim 60 \%$ compared with the control group, which underscores 
A

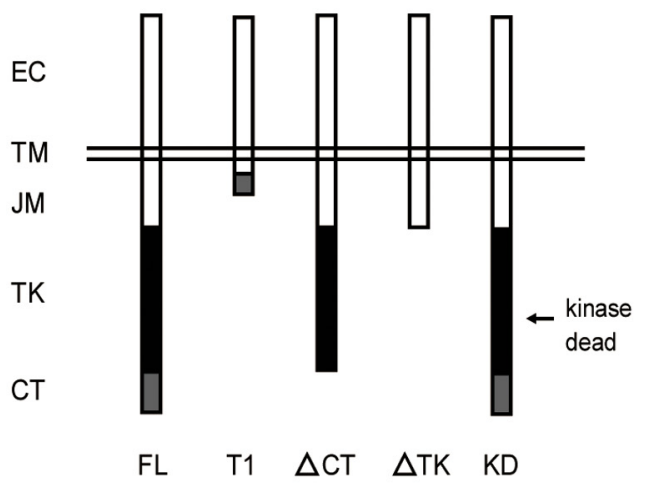

C

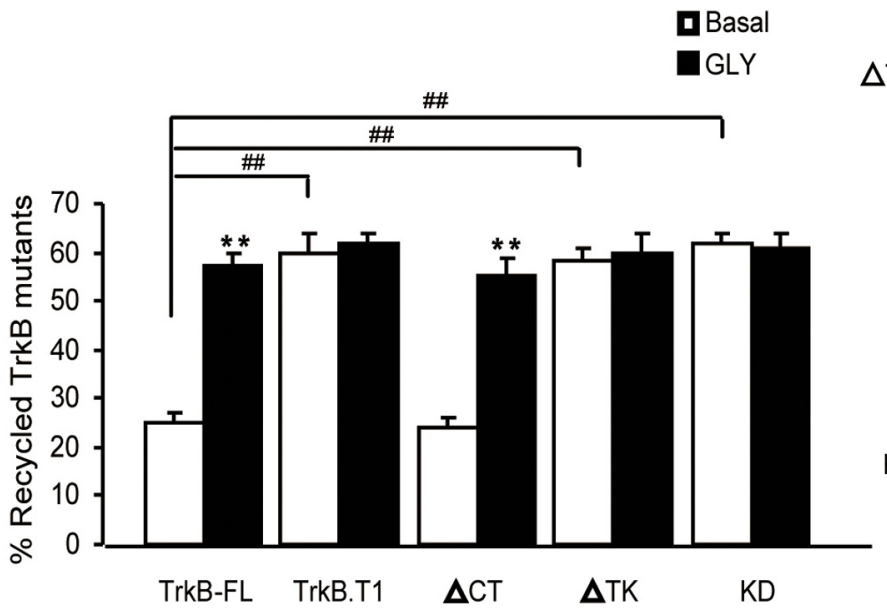

B
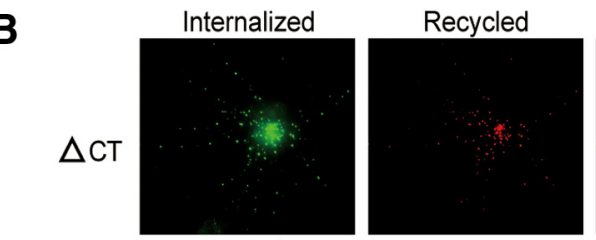

$\triangle \mathrm{CT}+\mathrm{GLY}$

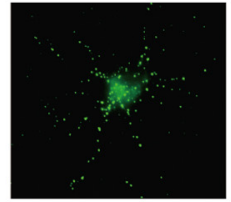

$\triangle T K$
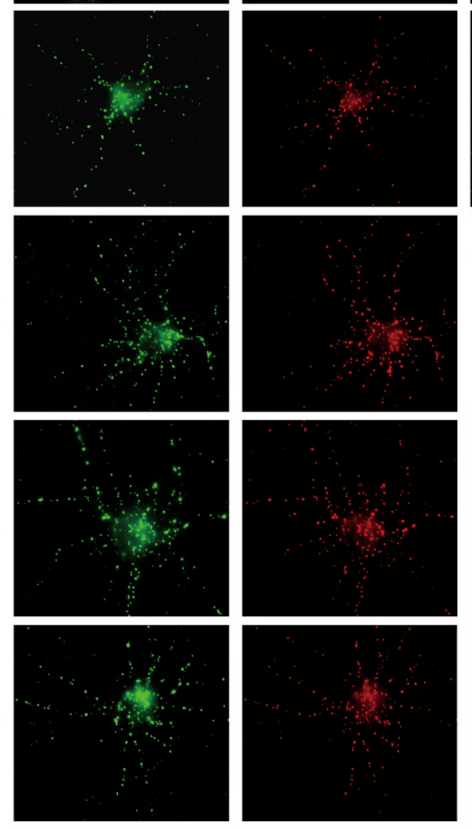

KD

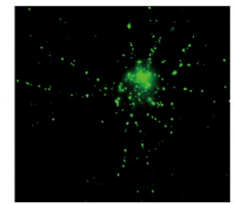

$\mathrm{KD}+\mathrm{GLY}$
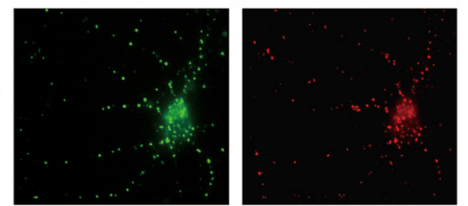
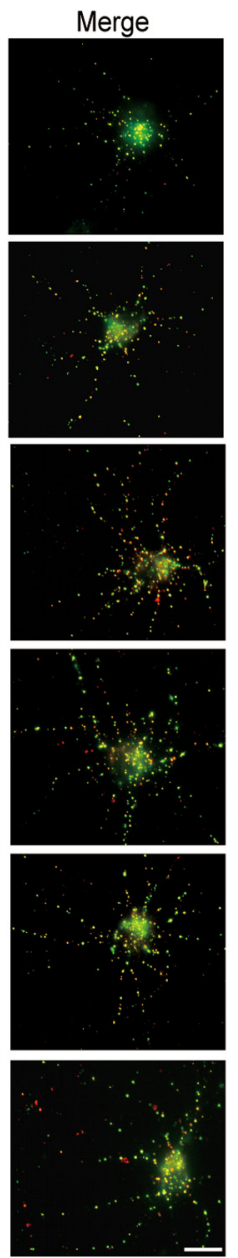

Figure 3. TrkB kinase domain is essential for cLTP-enhanced TrkB-FL recycling. A, Schematic presentation of FLAG-tagged TrkB-FL, TrkB.T1, and its mutants. $\Delta C T$ indicates that the CT region was deleted; $\Delta$ TK indicates that both the TK and CT regions were deleted; $K D$ indicates TrkB kinase-dead mutant (K571A). B, Representative immunofluorescence images of recycled TrkB mutants in transfected hippocampal neurons (9 DIV) with or without glycine treatment. The internalized TrkB receptors are shown in green and the recycled TrkB is shown in red. Scale bars, $20 \mu \mathrm{m}$. $C$, Quantitative analysis of TrkB mutant recycling levels in hippocampal neurons expressing the indicated constructs. Graphs represent means \pm SEM. of five independent experiments $(n \geq 30$ cells for each condition per experiment, ${ }^{* *} p<0.01$, compared with their respective baselines, ${ }^{\# \#} p<0.01$ compared with basal TrkB-FL recycling level, Student's $t$ test).

the importance of Rab11-dependent TrkB recycling pathway for efficient BDNF-induced sustained signaling. Moreover, knockdown of Rab11 abolished the cLTP-stimuli-enhanced BDNF downstream signaling (Fig. 6E-H). The altered BDNF-induced signaling was due to the redelivery of TrkB-FL receptors to the cell surface via the Rab11-dependent recycling pathway, because the cell surface and phosphorylation levels of TrkB-FL were accordingly changed in the presence of glycine pretreatment or by Rab11 knock-down (Figs. $1 F, 5 G, 6 E, F$ ).

\section{cLTP-enhanced recycling facilitates TrkB-FL translocation into postsynaptic density}

Ultrastructural analysis has indicated a large variety of recycling compartments and vesicles that serve multiple dendritic spines, most of which had recycling endosomes at their base (Cooney et al., 2002; Park et al., 2006). To determine whether postendocytic recycling could contribute to the translocation of TrkB-FL receptors to synapse, we first detected the localization of endogenous TrkB-FL receptors in dendritic spines. Hippocampal neurons (18 DIV) were transfected with GFP to show the shape of spines and the localization of endogenous TrkB was visualized by immunocytochemical staining with the C-terminal TrkB-FL antibodies that could specifically detect TrkB-FL but not TrkB.T1 (Fig. 7A). As shown in Figure $7 B, C$, we divided dendritic spines into three parts: at the base of spines, in the spine neck, and in the spine head. Quantitative analyses revealed that, under basal conditions, TrkB-FL receptors were predominantly localized in the dendritic shaft at the base of spines and only $26 \%$ of the spines contained TrkB-FL in the head. Compared with the baseline, BDNF treatment for $1 \mathrm{~h}$ significantly decreased the percentage of spines containing TrkB-FL at the base and accordingly increased the percentage of the spines $(\sim 41 \%)$ containing TrkB-FL in the head (Fig. 7C), which suggests that BDNF-triggered TrkB-FL endocytosis might facilitate its translocation into spines. Moreover, treatment of neurons with the endocytic recycling inhibitor monensin $(10 \mu \mathrm{M})$,could attenuate, whereas glycine pretreatment could enhance, the BDNF-induced TrkB-FL translocation into the spines (Fig. 7C), which supports the hypothesis that postendocytic recycled TrkB-FL receptors could translocate into spines.

Previous studies had indicated that $\operatorname{TrkB}$ was found in the postsynaptic density (PSD) (Ji et al., 2005). To monitor the localization of recycled TrkB receptors directly, hippocampal neurons were transfected with FLAG-TrkB-FL or FLAG-TrkB.T1 and then a live-cell antibody feeding assay was used to specifically 
A

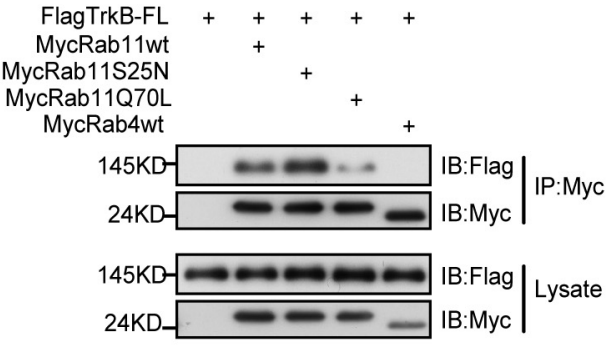

B MycRab11wt +++++

$\begin{array}{lllll}\text { MycRab11wt } & + & + & + & + \\ \text { FlagTrkB-FL } & & + & & \\ \text { FlagTrkB.T1 } & & & + & \\ \text { FlagTrkB.KD } & & & & +\end{array}$

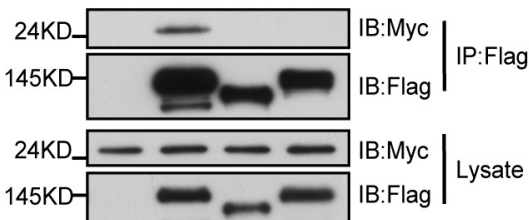

C

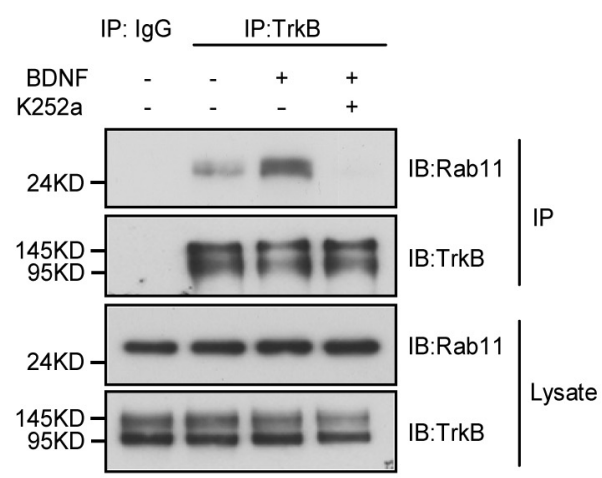

D
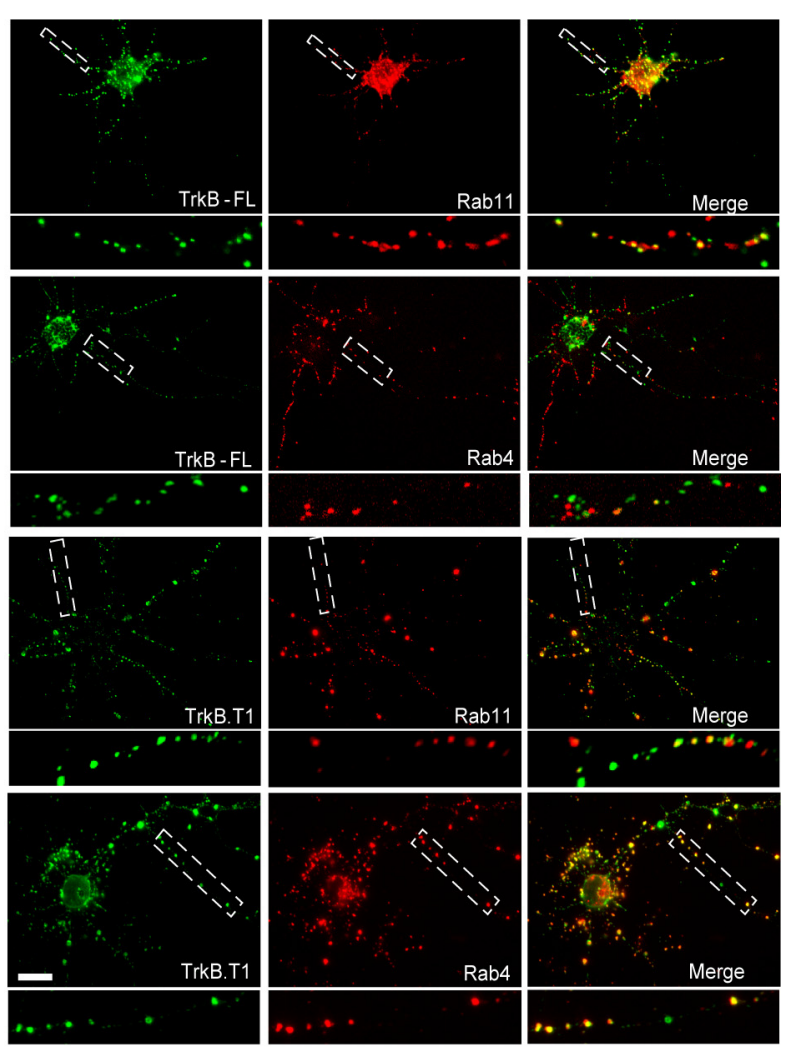

E

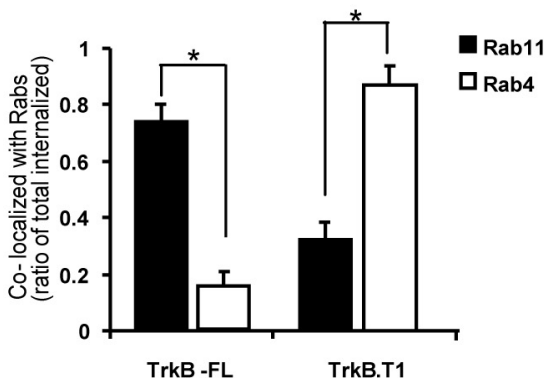

Figure 4. Rab11 interacts and colocalizes with TrkB-FL. A, CO-IP was performed in lysates of HEK293 cells expressing FLAG-tagged TrkB-FL and Myc-tagged Rab11 mutants or Myc-Tagged Rab4. Cell lysates were immunoprecipitated with anti-Myc antibodies. B, FLAG-tagged TrkB mutants were coexpressed with Myc-tagged Rab11wt in HEK293 cells. Cell lysates was immunoprecipitated with anti-FLAG antibodies. $C$, Endogenous association of Rab11 with TrkB was detected in cultured hippocampal neurons ( $9 \mathrm{DIV})$ under the indicated conditions by $\mathrm{C} 0 \mathrm{-IP}$. A preimmune IgG (Rb) was used as a negative control. Each C 0 -IP experiment $(\boldsymbol{A}-\boldsymbol{C})$ was repeated three times and representative data are shown. $\boldsymbol{D}$, Colocalization of internalized TrkB (derived by BDNF stimulation for 20 min, shown in green) with Rab11 (red) or Rab4 (red) in hippocampal neurons. Hippocampal neurons (9 DIV) transfected with FLAG tagged TrkB and MycRabs were starved overnight, fed with anti-FLAG antibodies (M1) for $30 \mathrm{~min}$, treated with BDNF $(50 \mathrm{ng} / \mathrm{ml})$ for $20 \mathrm{~min}$, fixed, and immunostained with anti-Myc antibody. Bottom: Higher magnification of vesicles. Scale bars, $20 \mu \mathrm{m}$. $E$, Colocalization quantification of internalized TrkB and Rabs. Data are shown as the mean \pm SEM ( $n \geq 30$ cells for each condition per experiment, ${ }^{*} p<0.05$, Student's $t$ test).

label the recycled TrkB receptors (Fig. 7D). Using our live-cell antibody feeding assay, we demonstrated the colocalization of recycled TrkB-FL with PSD-95 puncta and found that the percentage of their colocalization was significantly increased by glycine treatment (Fig. $7 D, E$ ). Compared with TrkB-FL, the recycled TrkB.T1 also colocalized with PSD-95, however, their colocalization was not further increased by glycine treatment (Fig. $7 D, E$ ). We next examined whether the Rab11-dependent recycling pathway is involved in the neuronal-activity-dependent delivery of recycled TrkB-FL to postsynaptic densities. Introducing in neurons the dominant-negative mutant of Rab11 (Rab11S25N) significantly decreased the colocalization percentage of recycled TrkB-FL with PSD-95 and abolished the glycinestimuli-induced increase in their colocalization (Fig. $7 D, E$ ). In addition, we found that the number of PSD-95 clusters was not changed after glycine treatment (Fig. $7 F$ ), which excluded the possibility that the glycine-enhanced colocalization between recycled TrkB-FL and PSD-95 puncta was caused by the increased number of PSD-95 clusters. These data indicate that cLTP stimuli could facilitate recycled TrkB-FL, but not TrkB.T1, translocation into postsynaptic densities via a Rab11-dependent pathway.

\section{Active form of Rab11 mediates the interaction between}

TrkB-FL and PSD-95

Previous studies have shown that TrkB-FL can physically interact with PSD-95 (Ji et al., 2005). We sought to determine whether Rab11 regulates this TrkB-FL/PSD-95 association. First, we performed CO-IP experiments to detect the association between 

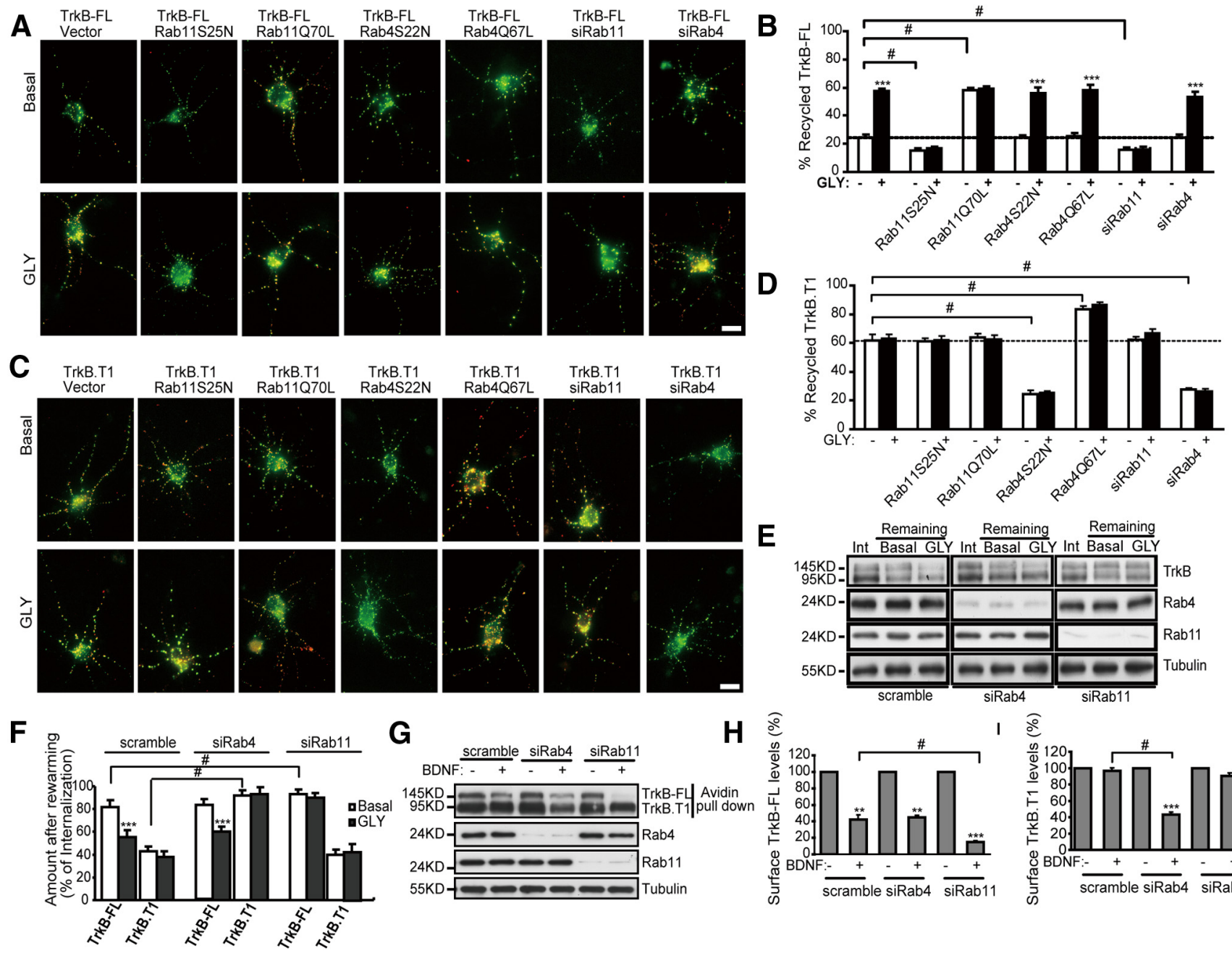

G
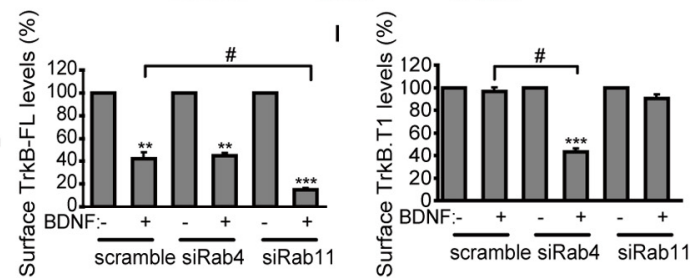

Figure 5. TrkB-FL and TrkB.T1 receptors are sorted into the Rab11- or Rab4-dependent recycling pathway, respectively. $A$, Representative immunofluorescence images of recycled TrkB-FL in neurons (9 DIV) expressing the indicated constructs. Scale bars, $20 \mu \mathrm{m}$. $\boldsymbol{B}$, Quantitative analysis of TrkB-FL recycling in neurons expressing the indicated constructs. Graphs represent means \pm SEM of three independent experiments ( $n \geq 30$ cells for each condition per experiment, ${ }^{* * *} p<0.001$ relative to their respective unstimulated group, ${ }^{\#} p<0.05$ relative to unstimulated TrkB-FL, Student's $t$ test). C, Representative immunofluorescence images of recycled TrkB.T1 in neurons expressing the indicated constructs. Scale bars, $20 \mu \mathrm{m}$. D, Quantitative analysis of TrkB.T1 recycling in neurons expressing the indicated constructs. Graphs represent means \pm SEM of three independent experiments $(n \geq 30$ cells for each condition per experiment, $\# p<0.05$ relative to unstimulated TrkB.T1, Student's $t$ test). $\boldsymbol{E}$, Neurons (9 DIV) were transfected by the indicated siRNA and the TrkB recycling levels were measured by cleavable surface biotinylation $2 \mathrm{~d}$ after transfection. Lane 1 shows the internalized biotinylated TrkB receptors before rewarming; lane 2 shows un-recycled (remaining) TrkB receptors after 30 min rewarming under basal conditions; lane 3 shows un-recycled (remaining) TrkB receptors after 30 min rewarming upon cLTP stimuli. $F$, Quantitation of remaining TrkB levels in $\boldsymbol{E}$. Bar graphs represent means $\pm S E M(n=5$, *** $p<0.001$ relative to their respective basal control, ${ }^{\#} p<0.05$, Student's $t$ test). $\mathbf{G}$, Neurons transfected with the indicated siRNA ( 9 DIV) were stimulated with BDNF for $1 \mathrm{~h}$, followed by surface biotinylation. $\boldsymbol{H}, \boldsymbol{I}$, Quantification of surface levels of TrkB-FL (D) and TrkB.T1 (E). Graphs represent means \pm SEM $\left(n=3,{ }^{* *} p<0.01,{ }^{* * *} p<0.001\right.$ relative to their respective no BDNF treatment group, ${ }^{\#} p<$ 0.05 , Student's $t$ test).

TrkB-FL and PSD-95 under conditions in which different Rab11 mutants or siRNA were cotransfected. We found that Rab11Q70L significantly increased the association between TrkB-FL and PSD-95, whereas Rab11S25N decreased this association (Fig. 8A). In addition, knock-down of Rab11 also inhibited the interaction between TrkB-FL and PSD-95 (Fig. 8A). These results indicate that the active form of Rab11 facilitates the association between TrkB-FL and PSD-95. The association between TrkB-FL and PSD-95 was further evaluated in the presence of a GDP or a nonhydrolyzable GTP-analog. CO-IP results revealed that GDP-bound Rab11 weakened, whereas GTP-bound Rab11 enhanced, the association between TrkB-FL and PSD-95 (Fig. $8 B)$. We further found that the GTP-bound, but not GDPbound, Rab11 could associate with PSD-95 in CO-IP experiments (Fig. 8C), which further supports our previous finding that the active form of Rab11 mediates the association between TrkB-FL and PSD-95.
To determine whether BDNF-dependent TrkB-FL recycling could facilitate the TrkB-FL/PSD-95 interaction under physiological conditions, we performed endogenous TrkB/PSD-95 CO-IP assays from cultured hippocampal slices. We treated hippocampal slice cultures $(\mathrm{P} 6+9 \mathrm{DIV})$ with recombinant BDNF for $1 \mathrm{~h}$ and the TrkB/PSD-95 association was then examined (Fig. $8 D)$. We found that BDNF treatment led to more PSD-95 being pulled down by TrkB immunoprecipitation. Moreover, cLTP stimuli significantly enhanced the interaction between TrkB-FL and PSD-95 (Fig. 8D). This result was consistent with our previous finding that cLTP stimuli could facilitate recycled TrkB-FL translocation to the PSD. To explore the molecular mechanism underlying this phenomenon, we investigated whether cLTP stimuli could increase the activity of Rab11, because only GTPbound Rab11 mediates TrkB-FL/PSD-95 interactions. It has been reported that the inactive Rab protein is in a soluble cytosolic form and the activated Rabs were membrane bound (Grosshans 
A

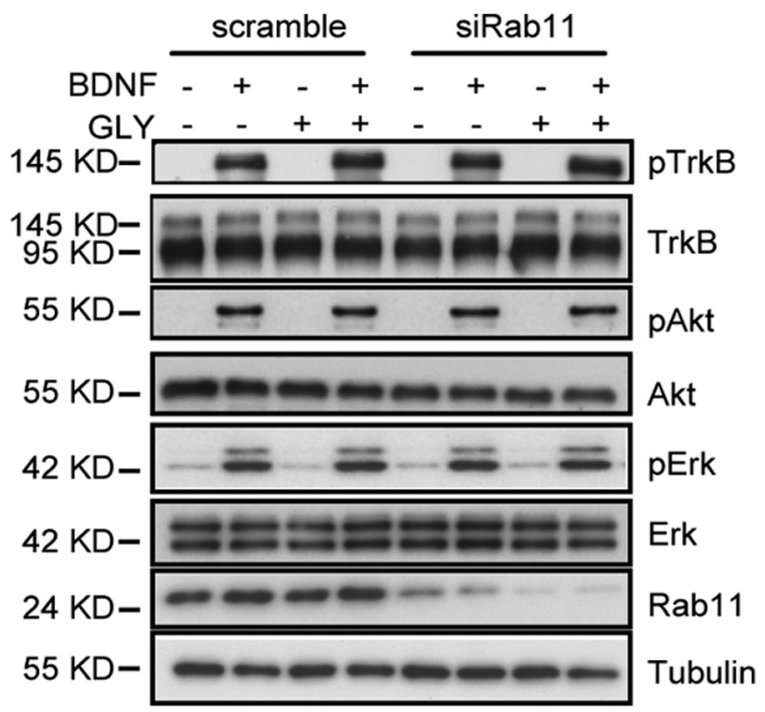

E

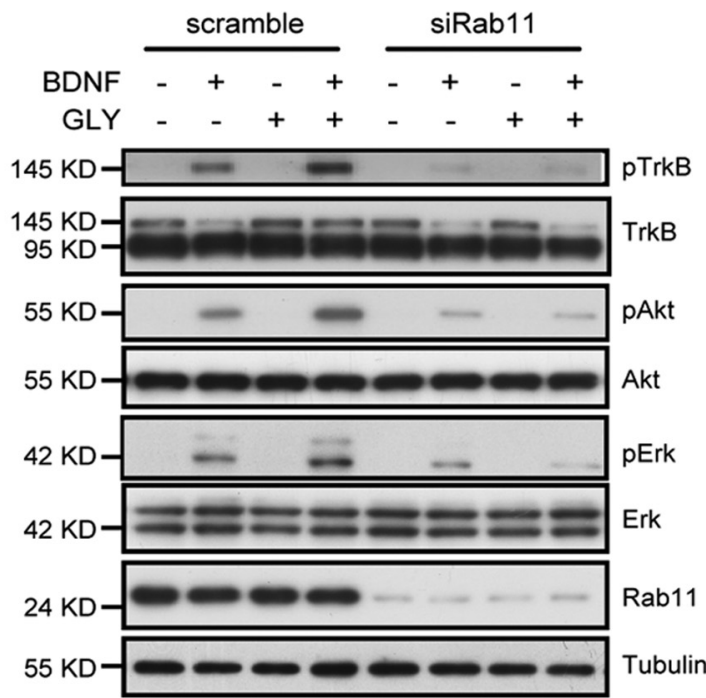

B

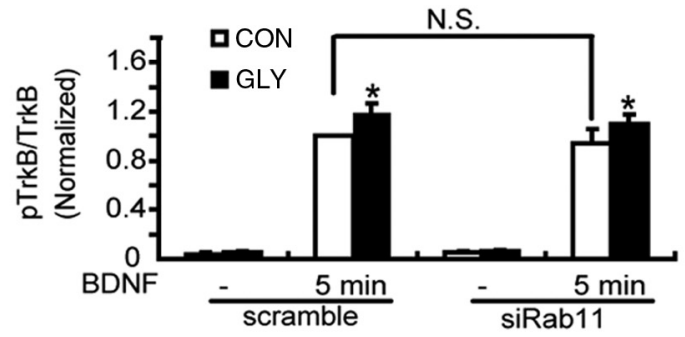

C

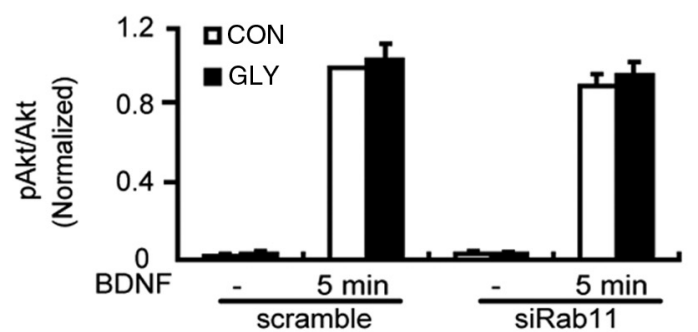

D

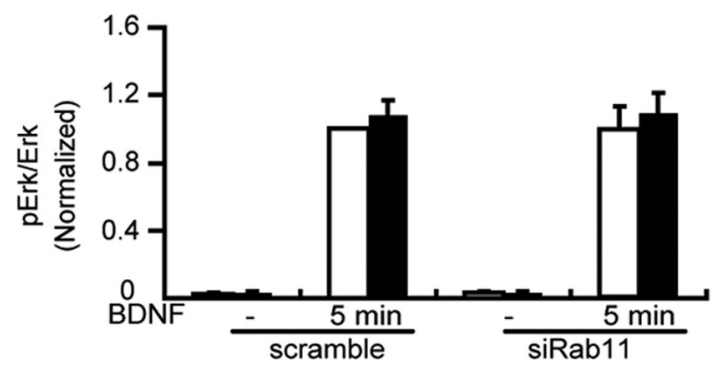

$\mathbf{F}$

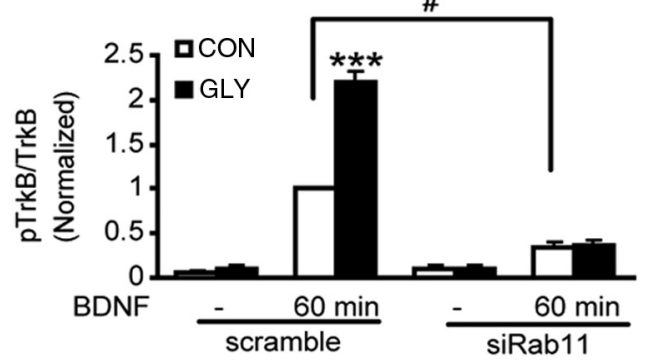

G

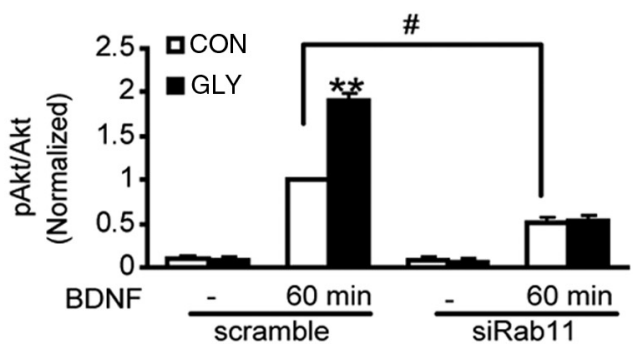

H

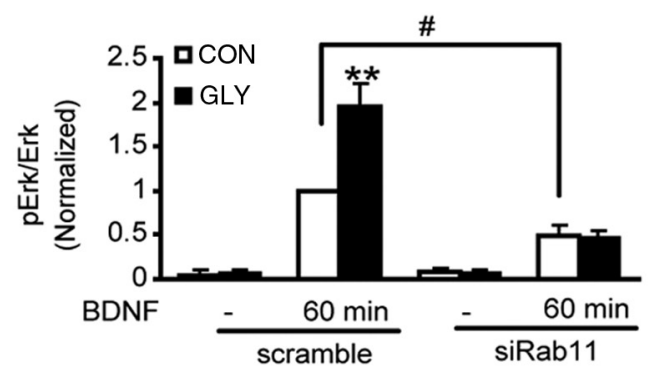

Figure 6. Increased TrkB-FL recycling upon cLTP stimuli enhances BDNF-induced sustained but not transient ERK and PI3K-AKT activation. A, Hippocampal neurons (7 DIV) were transfected with scrambled or siRab11 RNA as indicated. Two days later, the neurons were serum starved overnight and neurons with or without glycine (200 $\mu \mathrm{m}, 3$ min) before stimulation (Figure legend continues.) 
et al., 2006). As shown in Figure 8E, the distribution of Rab11 in cytosol or membrane fractions was analyzed by immunoblotting. We found that the total expression levels of Rab11 were not changed, but cLTP stimuli significantly increased the levels of membrane-bound Rab11 (Fig. 8E). In contrast, membranebound levels of Rab4 were not altered upon cLTP stimuli. A GST pull-down assay with Sec15, which has been shown to be an effector protein of Rab11 and only binds to GTP-bound Rab11 with its C-terminal domain (Zhang et al., 2004; Wu et al., 2005), was used to test the Rab11 activity directly. Bacterially expressed and immuno-mobilized GST-tagged Sec15C was incubated with the neuronal lysate (pretreated with glycine or not). The beads were subsequently washed and the bound proteins were analyzed by immunoblotting using anti-Rab11 antibody. As expected, an $\sim 2.5$-fold increase in the levels of Rab11 detected on the GSTSec15C beads was observed when neurons were pretreated with glycine (Fig. $8 F$ ). These results suggest that cLTP stimuli could facilitate the interaction between TrkB-FL and PSD by modulating the activity of Rab11.

\section{Neuronal-activity-dependent TrkB-FL recycling is involved in BDNF-induced neuronal survival}

Finally, we investigated the physiological significance of neuronalactivity-enhanced TrkB-FL recycling. It is well known that BDNF is a survival promoting factor for hippocampal neurons (Chao, 2003). We assessed the role of TrkB-FL recycling in the survival-promoting effect of BDNF on hippocampal neurons during serum deprivation. Using active caspase- 3 Western blot and TUNEL assay, we found that although bicuculline treatment alone had no effect on neuronal survival, it could significantly enhance the protection effect of BDNF on serum-deprivation-induced apoptosis of hippocampal neurons (Fig. 9A-D). Knocking down Rab11 abolished the bicuculline-enhanced survival-promoting effect of BDNF (Fig. $9 A-D)$, which suggested that neuronal-activity-dependent recycling of TrkB-FL is involved in the trophic actions of BDNF and explained at least in part the preferential effect of BDNF on active neurons.

\section{Discussion}

BDNF has emerged as a key regulator of activity-dependent synaptic plasticity. In the hippocampus, substantial evidence suggests that BDNF facilitates both early-phase and late-phase LTP, which are mediated by the binding and activation of TrkB receptor (Nagappan and Lu, 2005). Growing evidence has suggested that neuronal activity facilitates cell surface insertion of TrkB in a BDNF-independent manner from the biosynthetic secretion pathway (Meyer-Franke et al., 1998; Du et al., 2000; Zhao et al.,

\footnotetext{
(Figure legend continued.) were treated with BDNF $(50 \mathrm{ng} / \mathrm{ml})$ for 5 min and lysed. Total and phosphorylated protein levels were examined by immunoblotting. $\boldsymbol{B}-\boldsymbol{D}$, Quantitative analysis of TrkB (B), Akt ( $\boldsymbol{C}$, and Erk1/2 (D) activation. pTrk, pErk1/2, and pAkt levels were normalized to the phosphorylation levels of scramble group detected at the 5 min time point without glycine pretreatment. Graphs represent means $\pm \operatorname{SEM}\left(n=3,{ }^{*} p<0.05\right.$ relative to their respective control group, Student's $t$ test); N.S. indicates not significant. $E$, Hippocampal neurons (7 DIV) were transfected with scrambled or siRab11 RNA as indicated. Two days later, the neurons were serum starved overnight and neurons with or without glycine (200 $\mu \mathrm{m}, 3 \mathrm{~min}$ ) before stimulation were treated with BDNF $(50 \mathrm{ng} / \mathrm{ml})$ for 60 min and lysed. Total and phosphorylated protein levels were examined by immunoblotting. $\boldsymbol{F}-\boldsymbol{H}$, Quantitative analysis of $\operatorname{TrkB}(\boldsymbol{F}), \operatorname{Akt}(\boldsymbol{G})$, and Erk1/2 $(\boldsymbol{H})$ activation. pTrk, pErk1/2, and pAkt levels were normalized to the phosphorylation levels of scramble group detected at the 60 min time point without glycine pretreatment. Graphs represent means $\pm \mathrm{SEM}\left(n=3,{ }^{* *} p<0.01,{ }^{* * *} p<0.001\right.$ relative to their respective control group, ${ }^{\#} p<0.05$, Student's $t$ test).
}

2009). Here we provide evidence that neuronal activity could additionally enhance the recycling of endocytosed TrkB-FL receptor, but not its isoform TrkB.T1, in a BDNF-dependent manner via a Rab11-directed pathway. Moreover, enhanced TrkB-FL recycling could facilitate BDNF-induced sustained ERK and PI3K activation and supply more TrkB to the PSD during LTP. Therefore, the recycling endosome could serve as a reserve pool to supply TrkB-FL receptor for LTP maintenance.

Our results provide several new insights into the mechanism and significance of neuronal-activity-enhanced TrkB-FL recycling. First, we found that cLTP could significantly enhance the recycling of TrkB-FL receptors, but not the isoform TrkB.T1 receptors. It has been established that TrkB-FL and TrkB.T1 receptors are both efficiently endocytosed by BDNF treatment (Huang et al., 2009). Upon internalization, TrkB receptors are sorted in early endosomes either to a specialized recycling endosome compartment for reinsertion to the plasma membrane or to late endosomes and lysosomes for degradation (Chen et al., 2005). A recent study has shown that recycled and resecreted BDNF plays an important role in mediating the maintenance of LTP in hippocampal slices, which suggests a potential role of TrkB recycling in LTP regulation (Santi et al., 2006). We found that cLTP stimulation could block BDNF-induced TrkB-FL degradation, an effect that was abolished by coapplication of the NMDA receptor antagonist D-AP5. Using cleavable biotinylation and live cell ratiometric fluorescence-based recycling assays, we demonstrated that the BDNF-dependent postendocytic recycling of TrkB-FL, but not TrkB.T1, was significantly increased during CLTP stimuli. We further identified that the kinase activity is essential for the altered TrkB recycling in response to cLTP stimuli. TrkB.T1 is dynamically upregulated during fetal development and becomes the predominant Trk receptor isoform in the adult animal (Escandón et al., 1994). A number of studies have suggested that TrkB.T1 can inhibit TrkB-FL tyrosine kinase signaling through a dominant-negative mechanism both in vitro and in vivo (CarimTodd et al., 2009). The increased recycling of TrkB-FL, but not its isoform TrkB.T1, during cLTP could increase the cell surface TrkB-FL receptor levels and thus facilitate BDNF signaling for synaptic plasticity modulation.

Second, we found that the recycling of TrkB-FL and TrkB.T1 were respectively mediated by the Rab11- and Rab4-dependent pathways, which could explain their differential response to cLTP stimuli. We have previously found that recycling of endocytic TrkB-FL receptors occurs in a sequence-directed regulated recycling pathway that relies on its tyrosine kinase activity and hepatocyte growth factor-regulated tyrosine kinase substrate (Huang et al., 2009). In contrast, TrkB.T1 receptors recycle more efficiently after internalization via the default pathway (Huang et al., 2009). The relatively low levels of TrkB-FL recycling, although disadvantageous for functional recovery of signaling upon BDNF treatment, could be flexibly reprogrammed under different physiological conditions such as LTP. In the present study, we found that Rab11 could physically interact with TrkB-FL, but not TrkB.T1, which requires TrkB kinase activity, and that BDNF potentiates Rab11/TrkB-FL interaction via enhancing TrkB phosphorylation. A constitutively inactive form of Rab11 (Rab11S25N) impaired the endocytic recycling of TrkB-FL, but not TrkB.T1, whereas expression of the GTP-bound active form of Rab11 (Rab11Q70L) could significantly increase TrkB-FL recycling to levels comparable to those after cLTP stimuli. On the contrary, introduction of the dominant-negative form of Rab4 significantly inhibited TrkB.T1 recycling but had no effect on the recycling of TrkB-FL. 
A GFP / TrkB-FL
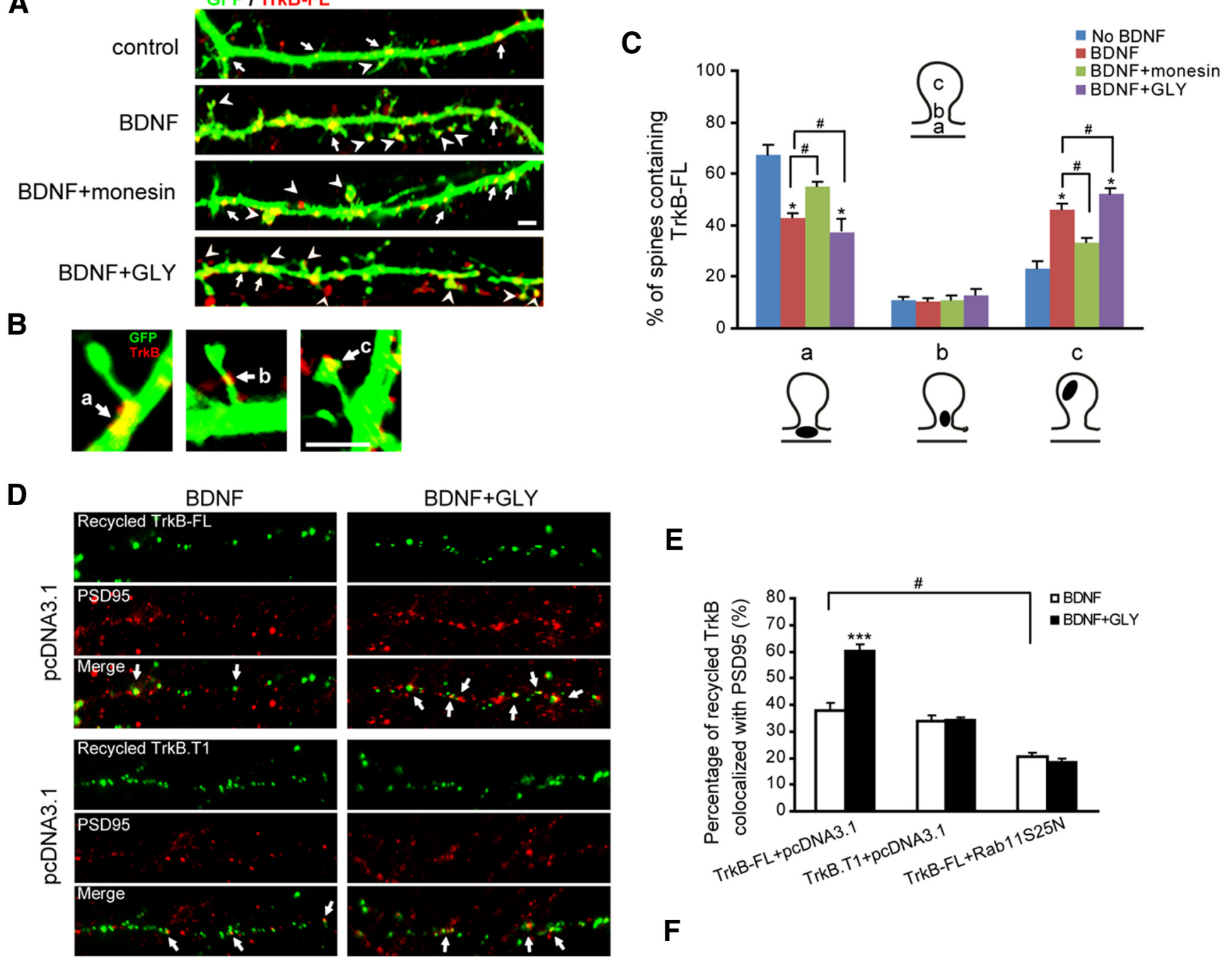

E
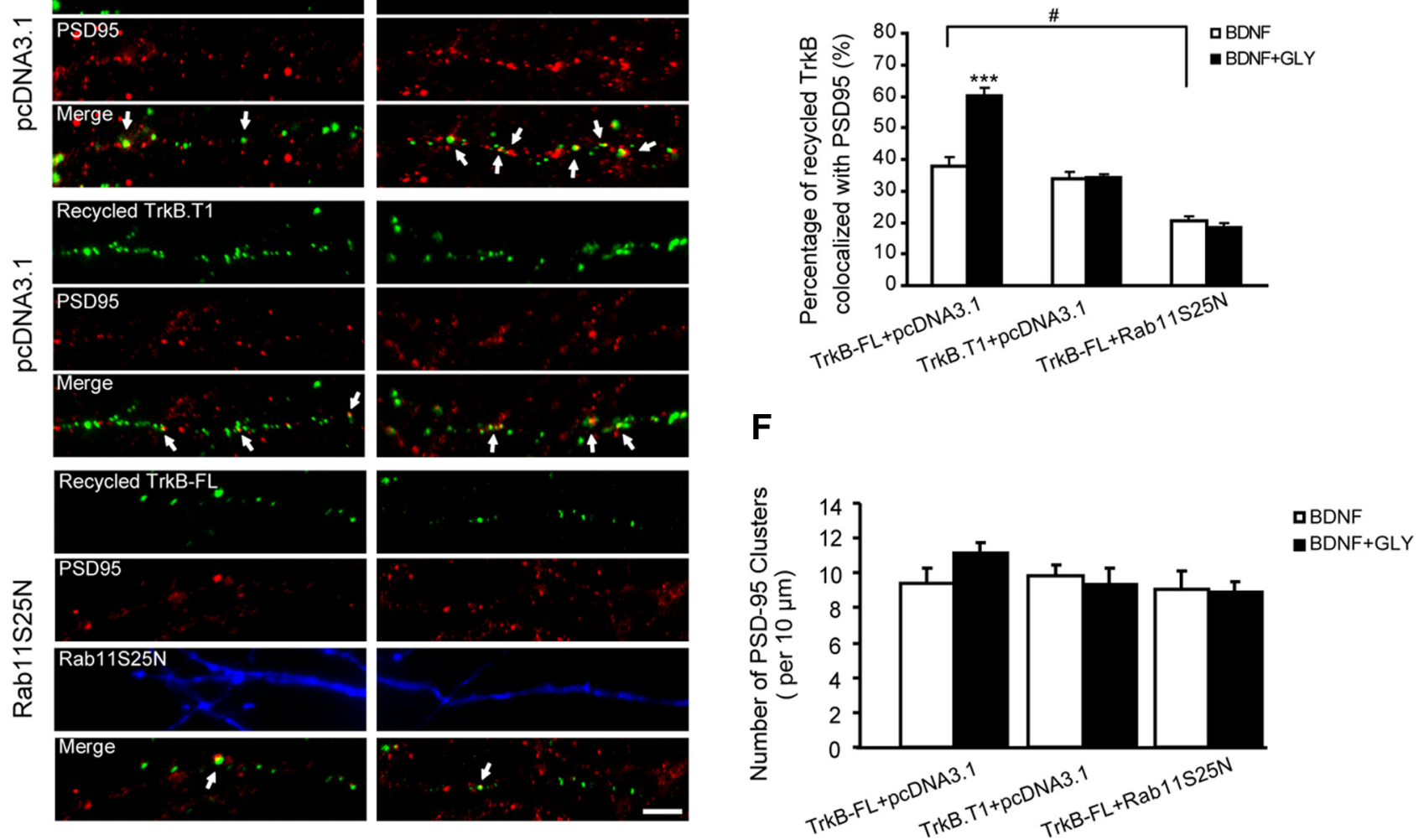

Figure 7. CLTP-enhanced recycling facilitates TrkB-FL translocation into postsynaptic densities. $A$, Hippocampal neurons (18 DIV) were transfected with GFP and treated with various agents as indicated. Endogenous TrkB-FL stained by the Trk (C-14) antibody that recognizes the C terminus of Trk (catalog\# sc-11; Santa Cruz Biotechnology) was labeled red. Arrowheads and arrows denote protrusions with and without TrkB in the spine head, respectively. Scale bars, $1 \mu \mathrm{m}$. $\boldsymbol{B}$, Three types of TrkB-FL distribution in spines. Scale bars, $2 \mu \mathrm{m}$. C, Proportions of spines containing TrkB-FL in the indicated locations. Graphs represent means $\pm \operatorname{SEM}\left(n=116,169\right.$, and 135 spines analyzed from 8,8 , and 10 neurons, respectively, ${ }^{*} p<0.05$ relative to no BDNF control of each group, ${ }^{\#} p<$ $0.05, \chi^{2}$ test. $\boldsymbol{D}$, Coimmunofluorescence labeling of recycled TrkB and PSD-95 in neurons (9 DIV) transfected with pcDNA3.1 or pCAGIG-GFP-Rab11525N. Hippocampal neurons were stained for recycled TrkB (green) and PSD-95 (red) with (left) or without (right) glycine stimulation. Blue indicates neurons expressing pcAGIG-GFP-Rab11S25N. Colocalization is indicated by white arrows. Scale bars, $10 \mu \mathrm{m}$. E, Quantification analysis of the colocalization of recycled TrkB-FL or TrkB.T1 with PSD-95 in D. Graphs represent means \pm SEM ( $n \geq 30$ cells for each condition per experiment, $* * * *<$ 0.001 relative to its baseline, ${ }^{\#} p<0.05$, Student's t test). $\boldsymbol{F}$, Quantification analysis of the clusters of PSD95. Images were taken using a 100 $\times$ objective and two-dimensional deconvolution software (MetaMorph) was used.

Rab proteins function as molecular switches and, when active, are anchored at the cytoplasmic face of membranous organelles, where they direct membrane trafficking events, such as vesicle formation, motility, docking, and fusion (Stenmark, 2009). Previous studies have shown that internalized receptors can be re- turned directly to the cell surface via the Rab4-dependent "fast" recycling pathway or recycled indirectly through the Rab11mediated "slow" pathway to the plasma membrane via the endosomal-recycling compartment (Sheff et al., 1999). Park et al. (2004) found GluA1-containing AMPARs inserted at the synap- 
A

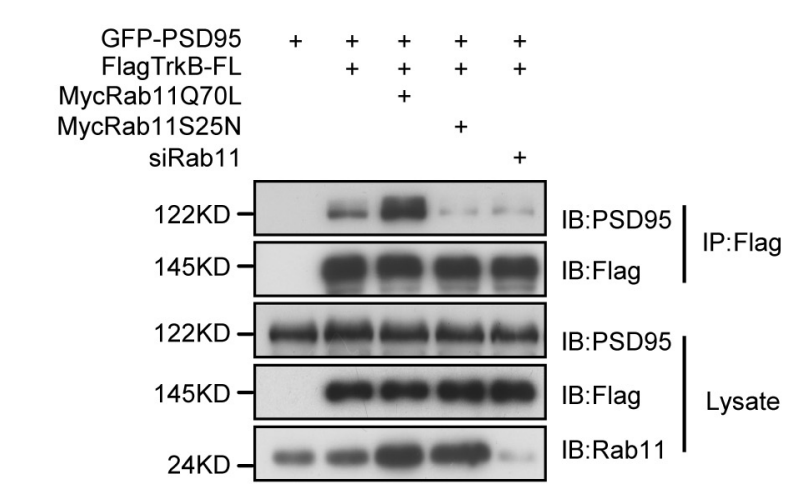

C

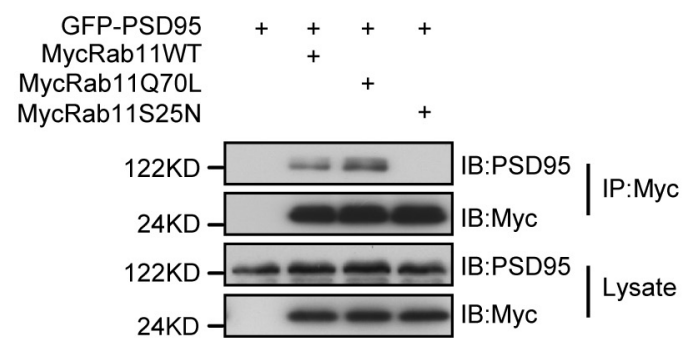

E
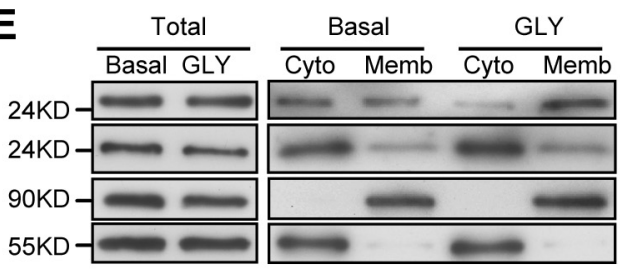

IB:Rab4

IB:Calnexin

IB:Tubulin
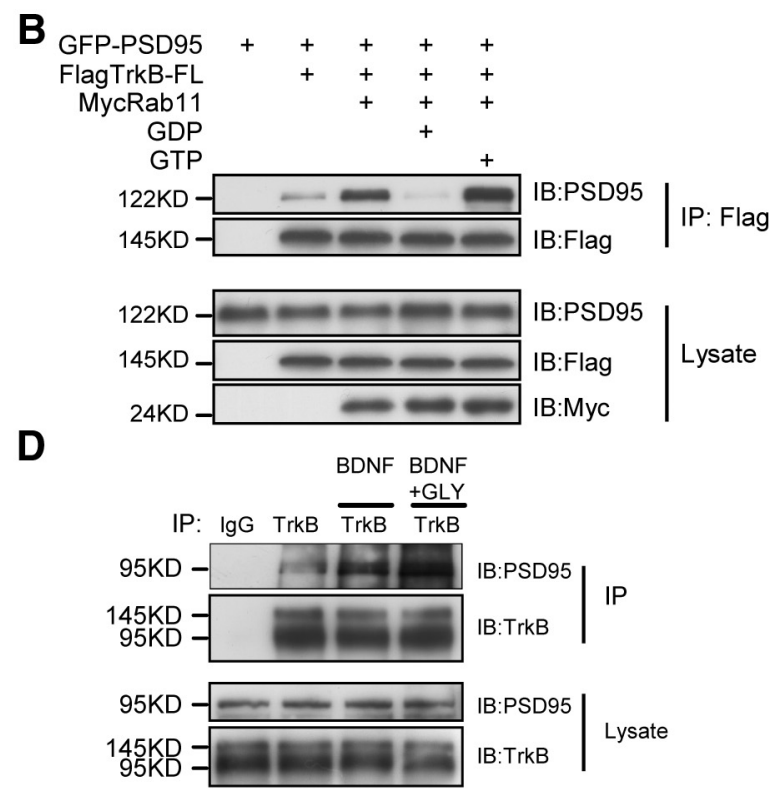

$\mathbf{F}$

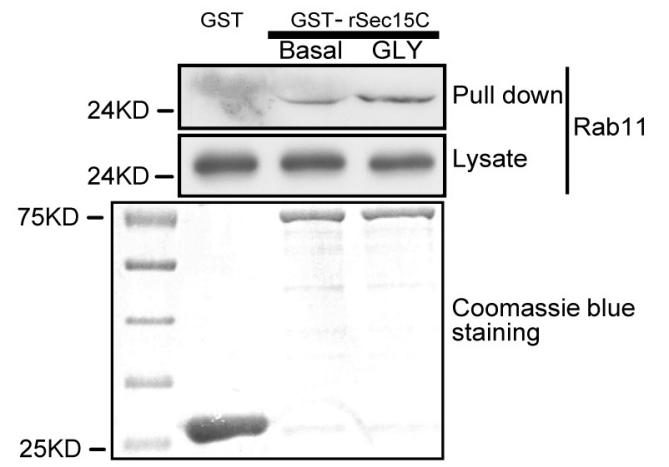

Figure 8. Rab11 modulates the interaction between TrkB-FL and PSD-95. A, Myc-tagged Rab11 mutants or Rab11 siRNA were transfected with FLAG-TrkB-FL and GFP-PSD-95 in HEK293 cells. Anti-FLAG immunoprecipitates were analyzed by immunoblotting with PSD-95 antibody. B, FLAG-TrkB-FL, GFP-PSD-95, and Myc-Rab11WT constructs were cotransfected into HEK293 cells as indicated. Proteins were then incubated in the presence of nonhydrolyzable GTP or GDP and immunoprecipitated with FLAG antibody. Then samples were analyzed by immunoblotting with indicated antibodies. C, CO-IP of different Rab11 mutants with PSD-95 as indicated. Cell lysate was immunoprecipitated with anti-Myc antibody and analyzed by immunoblotting with anti-PSD-95 antibody. D, Hippocampal organotypicslices (P6 + 9DIV, $400 \mu \mathrm{m}$ ) were stimulated with BDNF $(50 \mathrm{ng} / \mathrm{ml})$ for $1 \mathrm{~h}$ with or without glycine pretreatment and then slice lysate was immunoprecipitated with anti-TrkB antibody and analyzed by immunoblotting with anti-TrkB and PSD-95 antibodies. Nonimmune lgG was used as a negative control. E, Cultured hippocampal neurons were treated with glycine for $3 \mathrm{~min}$ and then washed out. One hour later, the neurons were homogenized and cytosol (Cyto) and membrane (Memb) fractions were extracted. The lysate was analyzed by immunoblotting with anti-Rab11 and Rab4 antibodies. Tubulin and calnexin were used as markers of cytosol and membrane protein, respectively. $\boldsymbol{F}$, Immobilized GST-Sec15c (lanes 2 and 3) or control GST (lane 1) was incubated with cultured neurons extract undergoing glycine pretreatment or not. The beads were subsequently washed and bound proteins were analyzed by immunoblotting using anti-Rab11 antibody. GST fusion proteins were detected by Coomassie blue staining (bottom). All experiments were repeated a minimum of three times and representative data are shown.

tic plasma membrane in response to LTP-inducing stimuli via Rab11-dependent recycling pathway. Interestingly, they found that LTP stimuli promoted recycling not only of AMPARs, but also of transferrin receptors, and suggested that LTP involves a global regulation of the recycling system, rather than a specific regulation of AMPAR trafficking through recycling endosomes. However, in our study, we demonstrated that cLTP could specifically enhance the recycling of TrkB-FL, but not TrkB.T1, which suggested that LTP might have a specific effect on Rab11dependent recycling pathway rather than globally regulate the recycling system. To support this notion, neuronal cells were found to have a central perinuclear transferrin-positive recycling endosome that contained both Rab11 GTPases and Rab11effector proteins (Hémar et al., 1997). In addition, neurons also have smaller transferrin/Rab11-positive endosomal-recycling compartment that are positioned at the base of dendritic spines (Ehlers, 2000; Cooney et al., 2002). The recycling of transferrin receptors is typically biphasic, with both initial rapid and later slow components. Expression of dominant-negative Rab11 has been shown to specifically inhibit transferrin receptor recycling (Daro et al., 1996; Ren et al., 1998). These studies suggested that the increased recycling of the transferrin receptors during LTP might also be mediated via the Rab11-dependent pathway.

In a previous study, Rab11 was shown to regulate the intracellular trafficking of the TP $\beta$ receptor by a direct interaction (Hamelin et al., 2005). Whether the association between TrkB and Rab11 is a direct interaction or is mediated by some adaptor proteins is still unclear. Furthermore, whether and how the TrkB/ Rab11 interaction affects the function of Rab11 is also a remaining question. Previous studies showed that the direct interaction between angiotensin II type 1A receptor and Rab5a could increase the amount of GTP loading onto the Rab5 GTPase, suggesting that the receptor may function as a GEF for Rab5a or that it may recruit protein complexes containing GEF (Seachrist et al., 
A

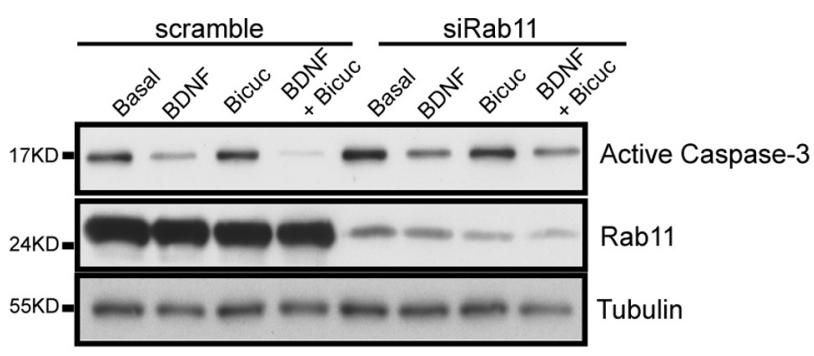

B

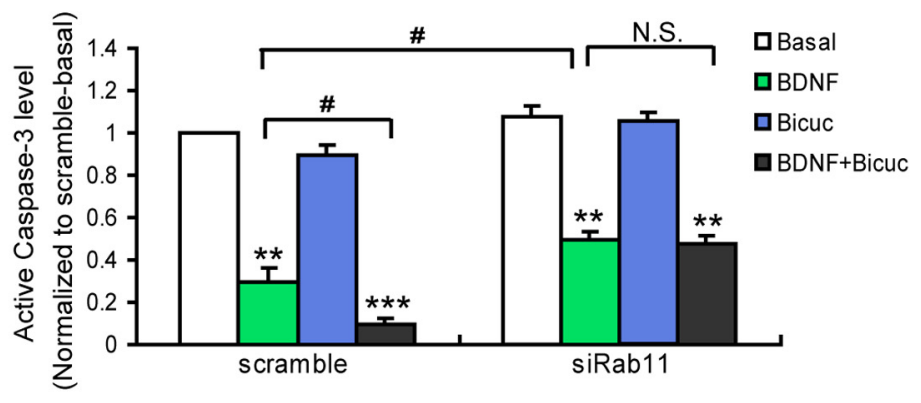

C
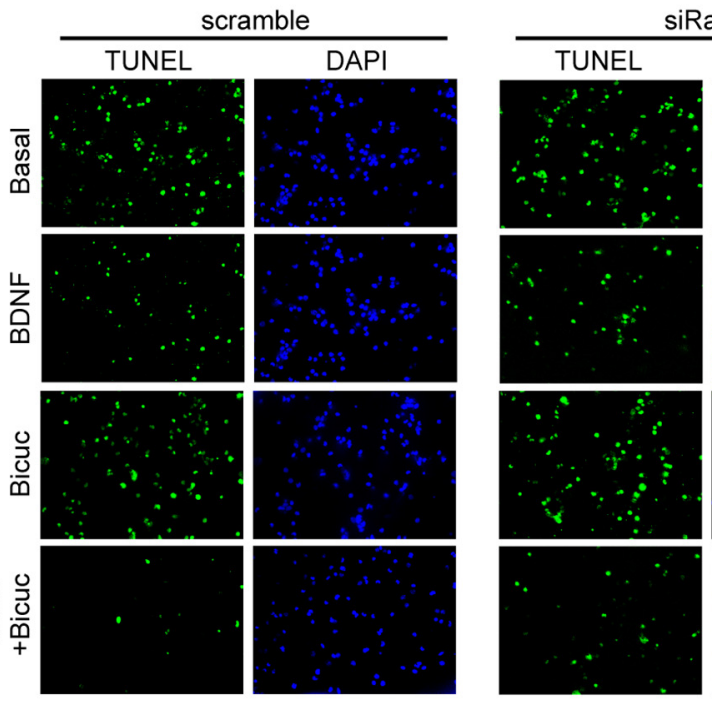

$\operatorname{siRab} 11$
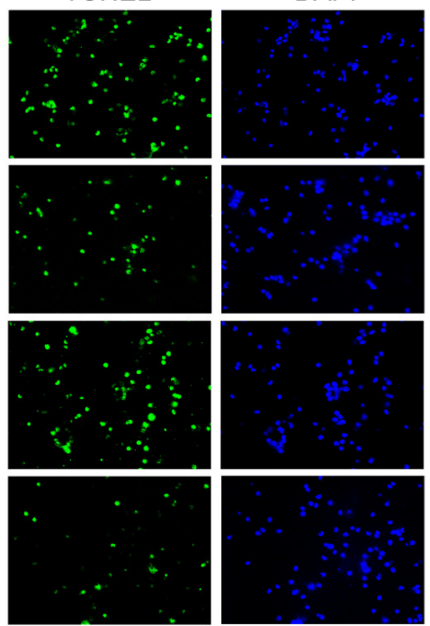

D

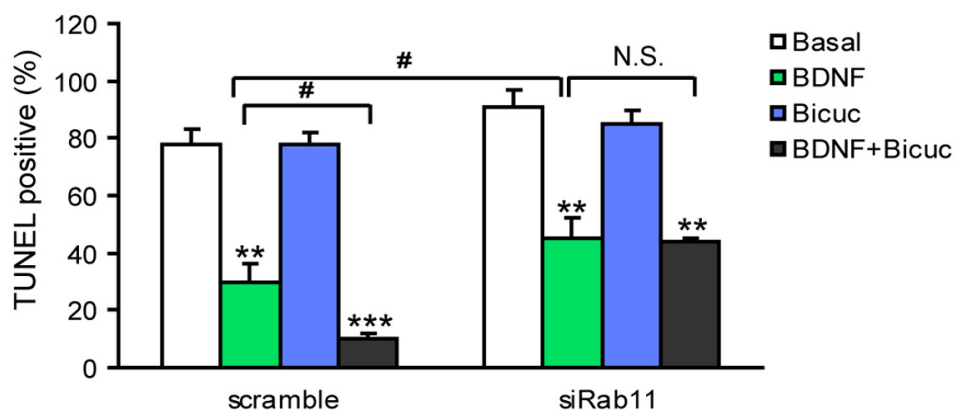

Figure 9. Neuronal-activity-dependent TrkB-FL recycling is involved in BDNF-induced neuronal survival. Hippocampal neurons (7 DIV) were transfected with the indicated siRNA. Two days later, the neurons were starved of B27 for $2 \mathrm{~d}$. Drugs ( $50 \mathrm{ng} / \mathrm{ml}$ BDNF and/or $10 \mu \mathrm{m}$ bicuculline) were applied to the cells as soon as B27 was removed. $A$, Immunoblotting analysis of cleaved caspase-3, Rab11, and tubulin. $\boldsymbol{B}$, Summary of densitometric analysis of cleaved caspase-3. The levels of cleaved caspase-3 were normalized to scramble-basal group. Data are presented as the mean \pm SEM $\left(n=3,{ }^{* *} p<0.01,{ }^{* * *} p<0.001\right.$ relative to the basal control of each group, ${ }^{\#} p<0.05$, one-way ANOVA). N.S. indicates not significant. C, Apoptosis was determined by TUNEL staining (green dots) $48 \mathrm{~h}$ after B27 deprivation and neurons were doubly stained with DAPI (blue dots). D. The percentage of cell death was quantified by dividing the number of apoptotic nuclei to a population of 2000 counted cells per condition. Graphs represent means \pm SEM $\left(n=3,{ }^{* *} p<0.01,{ }^{* * *} p<0.001\right.$ relative to the basal control of each group, ${ }^{\#} p<0.05$, one-way ANOVA). N.S. indicates not significant.

2002). Whether the TrkB/Rab11 complex could act as a GEF or GAP for Rab11 needs further investigation.

Third, we demonstrated that the increased TrkB-FL recycling could enhance BDNF-triggered sustained TrkB downstream signaling, facilitate TrkB-FL translocation to PSD during LTP, and promote the BDNF-induced hippocampal neuron survival. Previous studies have demonstrated that the activation of PI3K and ERK pathways play essential roles in LTP induction and maintenance (Man et al., 2003; Kelleher et al., 2004; Tsokas et al., 2007). Therefore, the potentiated sustained PI3K and ERK signaling induced by enhanced TrkB-FL recycling could contribute to the
LTP regulation. Moreover, we found that the increased TrkB-FL recycling stimulated by LTP could facilitate the movement of TrkB-FL into the PSD of hippocampal neurons, which was abolished by knock-down of Rab11. Previous studies have indicated that TrkB seems to be distributed throughout the neuron, including the soma, dendrite, and axon (Kryl et al., 1999), and that synaptic TrkB-FL receptors play an important role in synaptic transmission and LTP (Poo, 2001). To elicit synapse-specific modulation, it is crucial that functional TrkB is localized at the synapses and preferably modulated by synaptic activity. It has been shown that neuronal activity could enhance endocytosis of 
the BDNF-TrkB complex ( $\mathrm{Du}$ et al., 2003), so the increased TrkB-FL endocytosis and recycling during LTP could act synergistically to supply more functional TrkB receptors to the PSD for synaptic plasticity modulation. Previous studies have found that the delivery of new AMPARs during LTP into synapses requires two distinct steps. First, Rab11-driven endosomes mediate the translocation of AMPARs into spines and then Rab8 mediates the final insertion of AMPARs into the synaptic membrane (Brown et al., 2007). Whether other Rab proteins in addition to Rab11 are involved in LTP-induced TrkB-FL synapse translocation needs further investigation. Our study demonstrated that BDNFdependent TrkB-FL recycling is important in supplying a mobile pool of functional TrkB receptors to synapses and modulating TrkB signaling during LTP. Moreover, we demonstrated that neuronal-activity-enhanced TrkB-FL recycling could potentiate the survival-promoting effect of BDNF on hippocampal neurons.

Finally, we found that GTP-bound active Rab11 could enhance the interaction between TrkB-FL and PSD-95. cLTP stimuli could promote the switch of Rab11 to its active form and thus facilitate TrkB-FL binding with PSD-95, which could in part explain the cLTP-induced translocation of recycled TrkB-FL into PSD. Though TrkB-FL receptors have been shown previously to interact with PSD-95, and this interaction could be regulated by neuronal activity, the underlying molecular mechanism is still unclear (Yoshii and Constantine-Paton, 2007). To our knowledge, this is the first study to show that the GTP-bound, but not GDP-bound, Rab11 could mediate the interaction between TrkB and PSD-95. cLTP could stimulate the switch of Rab11 from an inactivated to an activated form and thus enhance the interaction between TrkB and PSD-95.

In summary, our studies provide evidence that neuronal activity could selectively promote BDNF-dependent TrkB-FL receptors recycling via a Rab11-dependent pathway, which could enhance the translocation of TrkB-FL into the PSD by facilitating the association of TrkB-FL with PSD-95. LTP-induced TrkB-FL transport from recycling endosomes to PSD provides an appealing mechanism for activity-dependent synapse modification. Not only might these findings provide insights into the mechanistic link between activity-dependent and neurotrophic-dependent modulation of CNS neurons and synapses, but they might also have general implications in the cell biology of Rab11-dependent recycling pathway in synaptic plasticity.

\section{References}

Arancio O, Chao MV (2007) Neurotrophins, synaptic plasticity and dementia. Curr Opin Neurobiol 17:325-330. CrossRef Medline

Ascaño M, Richmond A, Borden P, Kuruvilla R (2009) Axonal targeting of Trk receptors via transcytosis regulates sensitivity to neurotrophin responses. J Neurosci 29:11674-11685. CrossRef Medline

Brown TC, Correia SS, Petrok CN, Esteban JA (2007) Functional compartmentalization of endosomal trafficking for the synaptic delivery of AMPA receptors during long-term potentiation. J Neurosci 27:13311-13315. CrossRef Medline

Carim-Todd L, Bath KG, Fulgenzi G, Yanpallewar S, Jing D, Barrick CA, Becker J, Buckley H, Dorsey SG, Lee FS, Tessarollo L (2009) Endogenous truncated TrkB.T1 receptor regulates neuronal complexity and TrkB kinase receptor function in vivo. J Neurosci 29:678-685. CrossRef Medline

Chao MV (2003) Neurotrophins and their receptors: a convergence point for many signalling pathways. Nat Rev Neurosci 4:299-309. CrossRef Medline

Chen ZY, Ieraci A, Tanowitz M, Lee FS (2005) A novel endocytic recycling signal distinguishes biological responses of Trk neurotrophin receptors. Mol Biol Cell 16:5761-5772. CrossRef Medline

Cooney JR, Hurlburt JL, Selig DK, Harris KM, Fiala JC (2002) Endosomal compartments serve multiple hippocampal dendritic spines from a wide- spread rather than a local store of recycling membrane. J Neurosci 22: 2215-2224. Medline

Correia SS, Bassani S, Brown TC, Lis é MF, Backos DS, El-Husseini A, Passafaro M, Esteban JA (2008) Motor protein-dependent transport of AMPA receptors into spines during long-term potentiation. Nat Neurosci 11:457-466. CrossRef Medline

Cracco JB, Serrano P, Moskowitz SI, Bergold PJ, Sacktor TC (2005) Protein synthesis-dependent LTP in isolated dendrites of CA1 pyramidal cells. Hippocampus 15:551-556. CrossRef Medline

Cunha C, Brambilla R, Thomas KL (2010) A simple role for BDNF in learning and memory? Front Mol Neurosci 3:1. CrossRef Medline

Curtis DR, Duggan AW, Felix D, Johnston GA (1971) Bicuculline, an antagonist of GABA and synaptic inhibition in the spinal cord of the cat. Brain Res 32:69-96. CrossRef Medline

Daro E, van der Sluijs P, Galli T, Mellman I (1996) Rab4 and cellubrevin define different early endosome populations on the pathway of transferrin receptor recycling. Proc Natl Acad Sci U S A 93:9559-9564. CrossRef Medline

De Simoni A, Yu LM (2006) Preparation of organotypic hippocampal slice cultures: interface method. Nat Protoc 1:1439-1445. CrossRef Medline

Du J, Feng L, Yang F, Lu B (2000) Activity- and Ca(2+)-dependent modulation of surface expression of brain-derived neurotrophic factor receptors in hippocampal neurons. J Cell Biol 150:1423-1434. CrossRef Medline

Du J, Feng L, Zaitsev E, Je HS, Liu XW, Lu B (2003) Regulation of TrkB receptor tyrosine kinase and its internalization by neuronal activity and $\mathrm{Ca}^{2+}$ influx. J Cell Biol 163:385-395. CrossRef Medline

Ehlers MD (2000) Reinsertion or degradation of AMPA receptors determined by activity-dependent endocytic sorting. Neuron 28:511-525. CrossRef Medline

Escandón E, Soppet D, Rosenthal A, Mendoza-Ramírez JL, Szönyi E, Burton LE, Henderson CE, Parada LF, Nikolics K (1994) Regulation of neurotrophin receptor expression during embryonic and postnatal development. J Neurosci 14:2054-2068. Medline

Figurov A, Pozzo-Miller LD, Olafsson P, Wang T, Lu B (1996) Regulation of synaptic responses to high-frequency stimulation and LTP by neurotrophins in the hippocampus. Nature 381:706-709. CrossRef Medline

Ghosh A, Carnahan J, Greenberg ME (1994) Requirement for BDNF in activity-dependent survival of cortical neurons. Science 263:1618-1623. CrossRef Medline

Greenberg ME, Xu B, Lu B, Hempstead BL (2009) New insights in the biology of BDNF synthesis and release: implications in CNS function. J Neurosci 29:12764-12767. CrossRef Medline

Grosshans BL, Ortiz D, Novick P (2006) Rabs and their effectors: achieving specificity in membrane traffic. Proc Natl Acad Sci U S A 103:1182111827. CrossRef Medline

Hamelin E, Thériault C, Laroche G, Parent JL (2005) The intracellular trafficking of the $\mathrm{G}$ protein-coupled receptor TPbeta depends on a direct interaction with Rab11. J Biol Chem 280:36195-36205. CrossRef Medline

Hémar A, Olivo JC, Williamson E, Saffrich R, Dotti CG (1997) Dendroaxonal transcytosis of transferrin in cultured hippocampal and sympathetic neurons. J Neurosci 17:9026-9034. Medline

Hoogenraad CC, Popa I, Futai K, Martinez-Sanchez E, Sanchez-Martinez E, Wulf PS, van Vlijmen T, Dortland BR, Oorschot V, Govers R, Monti M, Heck AJ, Sheng M, Klumperman J, Rehmann H, Jaarsma D, Kapitein LC, van der Sluijs P (2010) Neuron specific Rab4 effector GRASP-1 coordinates membrane specialization and maturation of recycling endosomes. PLoS Biol 8:e1000283. CrossRef Medline

Huang EJ, Reichardt LF (2003) Trk receptors: roles in neuronal signal transduction. Annu Rev Biochem 72:609-642. CrossRef Medline

Huang SH, Zhao L, Sun ZP, Li XZ, Geng Z, Zhang KD, Chao MV, Chen ZY (2009) Essential role of Hrs in endocytic recycling of full-length TrkB receptor but not its isoform TrkB.T1. J Biol Chem 284:15126-15136. CrossRef Medline

Isaac JT, Nicoll RA, Malenka RC (1995) Evidence for silent synapses: implications for the expression of LTP. Neuron 15:427-434. CrossRef Medline

Ji Y, Pang PT, Feng L, Lu B (2005) Cyclic AMP controls BDNF-induced TrkB phosphorylation and dendritic spine formation in mature hippocampal neurons. Nat Neurosci 8:164-172. CrossRef Medline

Kelleher RJ 3rd, Govindarajan A, Jung HY, Kang H, Tonegawa S (2004) Translational control by MAPK signaling in long-term synaptic plasticity and memory. Cell 116:467-479. CrossRef Medline 
Klein R, Conway D, Parada LF, Barbacid M (1990) The trkB tyrosine protein kinase gene codes for a second neurogenic receptor that lacks the catalytic kinase domain. Cell 61:647-656. CrossRef Medline

Korte M, Carroll P, Wolf E, Brem G, Thoenen H, Bonhoeffer T (1995) Hippocampal long-term potentiation is impaired in mice lacking brainderived neurotrophic factor. Proc Natl Acad Sci U S A 92:8856-8860. CrossRef Medline

Kryl D, Yacoubian T, Haapasalo A, Castren E, Lo D, Barker PA (1999) Subcellular localization of full-length and truncated Trk receptor isoforms in polarized neurons and epithelial cells. J Neurosci 19:5823-5833. Medline

Liao D, Hessler NA, Malinow R (1995) Activation of postsynaptically silent synapses during pairing-induced LTP in CA1 region of hippocampal slice. Nature 375:400-404. CrossRef Medline

Lu W, Man H, Ju W, Trimble WS, MacDonald JF, Wang YT (2001) Activation of synaptic NMDA receptors induces membrane insertion of new AMPA receptors and LTP in cultured hippocampal neurons. Neuron 29:243-254. CrossRef Medline

Man HY, Wang Q, Lu WY, Ju W, Ahmadian G, Liu L, D’Souza S, Wong TP, Taghibiglou C, Lu J, Becker LE, Pei L, Liu F, Wymann MP, MacDonald JF, Wang YT (2003) Activation of PI3-kinase is required for AMPA receptor insertion during LTP of mEPSCs in cultured hippocampal neurons. Neuron 38:611-624. CrossRef Medline

Meyer-Franke A, Wilkinson GA, Kruttgen A, Hu M, Munro E, Hanson MG Jr, Reichardt LF, Barres BA (1998) Depolarization and cAMP elevation rapidly recruit TrkB to the plasma membrane of CNS neurons. Neuron 21:681-693. CrossRef Medline

Moore AN, Waxham MN, Dash PK (1996) Neuronal activity increases the phosphorylation of the transcription factor cAMP response elementbinding protein (CREB) in rat hippocampus and cortex. J Biol Chem 271:14214-14220. CrossRef Medline

Nagappan G, Lu B (2005) Activity-dependent modulation of the BDNF receptor TrkB: mechanisms and implications. Trends Neurosci 28: 464-471. CrossRef Medline

Parent A, Hamelin E, Germain P, Parent JL (2009) Rab11 regulates the recycling of the beta2-adrenergic receptor through a direct interaction. Biochem J 418:163-172. CrossRef Medline

Park M, Penick EC, Edwards JG, Kauer JA, Ehlers MD (2004) Recycling endosomes supply AMPA receptors for LTP. Science 305:1972-1975. CrossRef Medline

Park M, Salgado JM, Ostroff L, Helton TD, Robinson CG, Harris KM, Ehlers MD (2006) Plasticity-induced growth of dendritic spines by exocytic trafficking from recycling endosomes. Neuron 52:817-830. CrossRef Medline

Patterson SL, Abel T, Deuel TA, Martin KC, Rose JC, Kandel ER (1996) Recombinant BDNF rescues deficits in basal synaptic transmission and hippocampal LTP in BDNF knockout mice. Neuron 16:1137-1145. CrossRef Medline

Poo MM (2001) Neurotrophins as synaptic modulators. Nat Rev Neurosci 2:24-32. CrossRef Medline

Ren M, Xu G, Zeng J, De Lemos-Chiarandini C, Adesnik M, Sabatini DD
(1998) Hydrolysis of GTP on rab11 is required for the direct delivery of transferrin from the pericentriolar recycling compartment to the cell surface but not from sorting endosomes. Proc Natl Acad Sci U S A 95:61876192. CrossRef Medline

Rose CR, Blum R, Kafitz KW, Kovalchuk Y, Konnerth A (2004) From modulator to mediator: rapid effects of BDNF on ion channels. Bioessays 26:1185-1194. CrossRef Medline

Santi S, Cappello S, Riccio M, Bergami M, Aicardi G, Schenk U, Matteoli M, Canossa M (2006) Hippocampal neurons recycle BDNF for activitydependent secretion and LTP maintenance. EMBO J 25:4372-4380. CrossRef Medline

Saxena S, Howe CL, Cosgaya JM, Steiner P, Hirling H, Chan JR, Weis J, Krüttgen A (2005) Differential endocytic sorting of p75NTR and TrkA in response to NGF: a role for late endosomes in TrkA trafficking. Mol Cell Neurosci 28:571-587. CrossRef Medline

Seachrist JL, Laporte SA, Dale LB, Babwah AV, Caron MG, Anborgh PH, Ferguson SS (2002) Rab5 association with the angiotensin II type 1A receptor promotes Rab5 GTP binding and vesicular fusion. J Biol Chem 277:679-685. CrossRef Medline

Segal RA (2003) Selectivity in neurotrophin signaling: theme and variations. Annu Rev Neurosci 26:299-330. CrossRef Medline

Sheff DR, Daro EA, Hull M, Mellman I (1999) The receptor recycling pathway contains two distinct populations of early endosomes with different sorting functions. J Cell Biol 145:123-139. CrossRef Medline

Stenmark H (2009) Rab GTPases as coordinators of vesicle traffic. Nat Rev Mol Cell Biol 10:513-525. CrossRef Medline

Tsokas P, Ma T, Iyengar R, Landau EM, Blitzer RD (2007) Mitogenactivated protein kinase upregulates the dendritic translation machinery in long-term potentiation by controlling the mammalian target of rapamycin pathway. J Neurosci 27:5885-5894. CrossRef Medline

Wang Z, Edwards JG, Riley N, Provance DW Jr, Karcher R, Li XD, Davison IG, Ikebe M, Mercer JA, Kauer JA, Ehlers MD (2008) Myosin Vb mobilizes recycling endosomes and AMPA receptors for postsynaptic plasticity. Cell 135:535-548. CrossRef Medline

Wu S, Mehta SQ, Pichaud F, Bellen HJ, Quiocho FA (2005) Sec15 interacts with Rab11 via a novel domain and affects Rab11 localization in vivo. Nat Struct Mol Biol 12:879-885. CrossRef Medline

Yoshii A, Constantine-Paton M (2007) BDNF induces transport of PSD-95 to dendrites through PI3K-AKT signaling after NMDA receptor activation. Nat Neurosci 10:702-711. CrossRef Medline

Yu H, Wang Y, Pattwell S, Jing D, Liu T, Zhang Y, Bath KG, Lee FS, Chen ZY (2009) Variant BDNF Val66Met polymorphism affects extinction of conditioned aversive memory. J Neurosci 29:4056-4064. CrossRef Medline

Zhang XM, Ellis S, Sriratana A, Mitchell CA, Rowe T (2004) Sec15 is an effector for the Rab11 GTPase in mammalian cells. J Biol Chem 279: 43027-43034. CrossRef Medline

Zhao L, Sheng AL, Huang SH, Yin YX, Chen B, Li XZ, Zhang Y, Chen ZY (2009) Mechanism underlying activity-dependent insertion of TrkB into the neuronal surface. J Cell Sci 122:3123-3136. CrossRef Medline 